\title{
Morphologic Changes in Age-Related Maculopathy
}

\author{
MIKE KLIFFEN, ${ }^{1,2}$ THEO L. VAN DER SCHAFT, ${ }^{3}$ CORNELIA M. MOOY, ${ }^{1,2}$ AND PAULUS T.V.M. DE JONG ${ }^{4,5,6 *}$ \\ ${ }^{1}$ Institute of Ophthalmology, Erasmus University and University Hospital Dijkzigt, Rotterdam, The Netherlands \\ ${ }^{2}$ Institute of Pathology, Erasmus University and University Hospital Dijkzigt, Rotterdam, The Netherlands \\ ${ }^{3}$ Eye-Hospital, Rotterdam, The Netherlands \\ ${ }^{4}$ Institute of Bioophthalmics and Epidemiology, Erasmus University, Rotterdam, The Netherlands \\ ${ }^{5}$ The Netherlands Ophthalmic Research Institute, Amsterdam, The Netherlands \\ ${ }^{6}$ Academié Medical Center, Amsterdam, The Netherlands Department of Ophthalmology
}

\section{KEY WORDS basal laminar deposit; drusen; age-related macular degeneration; ARM; AMD}

\begin{abstract}
Age-related maculopathy (ARM) is a degenerative disorder of the central part of the retina with a rising prevalence in patients 50 years of age and older, and comprises different histopathological changes. The morphologic changes in ARM are described and illustrated with light-microscopical, electron microscopical, and fundus pictures. Furthermore, the most important biochemical data are given. The most prominent aging changes in early stages of ARM are drusen and basal laminar deposit (BLD), both extracellular deposits, that are assumed to be important in the development of ARM. Drusen accumulate within Bruch's membrane, whereas BLD is present between Bruch's membrane and the retinal pigment epithelium. Although the histopathologic characteristics of the deposits are well documented, the chemical composition has only been partly resolved. Biochemical analysis of these deposits is necessary to determine the source of the deposits and to find possible ways to avoid or treat them. The late stages of ARM, geographic atrophy, and neovascular (disciform) degeneration, are called age-related macular degeneration (AMD), and result in severe and irreversible visual impairment. Since there is still no adequate therapy for the majority of people disabled by AMD, and because of the aging population resulting in even more patients with this disease, it is necessary to intensify the research on ARM in order to prevent AMD or find a therapy for it. Microsc Res Tech 36:106-122, 1997. 인 1997 Wiley-Liss, Inc.
\end{abstract}

\section{INTRODUCTION}

Age-related maculopathy (ARM) is an age-related degenerative disorder of the central part of the retina, the macula lutea (yellow spot). Essentially, it is a clinical diagnosis based on funduscopical changes and mild loss of visual acuity. There is, however, a lack of data correlating clinical signs with the many different histopathological changes encountered in this disease. It is customary nowadays to call the late stages of ARM, geographic atrophy and neovascular (disciform) degeneration, age-related macular degeneration (AMD). The prevalence is about $1-7 \%$ in people over 60 , up to $15 \%$ over age 85, and still rising because of the increasing age of the population (Ferris, 1983; Klein and Klein, 1982; Leibowitz et al., 1980; Vinding, 1989; Vingerling et al., 1994). In fact, AMD is the commonest cause of blindness in the elderly in the western world (Ferris, 1983; Leibowitz et al., 1980). Although this disease has been known for more than a century (Haab, 1888), knowledge on the pathogenesis of the affliction is still incomplete. In this review the morphologic changes in the aging human macula will be discussed, and the appearance by funduscopic examination will be shown where appropriate. Although the causal relationship between subsequent stages of ARM has not been established, we describe the changes in ARM that usually appear in life in the different structures of the human macula. Each of these changes will be described separately and in the following order: a brief introduction of the structure, the appearance on funduscopic examina- tion, the (immuno)histopathology, and the ultrastructure (not all of these data are available for each structure). Thus, successively, age-related alterations in the neuro-retina, the retinal pigment epithelium (RPE), Bruch's membrane with drusen and basal laminar deposit (BLD), the choriocapillaris, and the choroid, will be reviewed. For a better understanding of the terminology a brief description of the most important structures of the normal human macula will be given in the first paragraph.

\section{ANATOMY OF THE NORMAL HUMAN MACULA}

The macula lutea, also called the yellow spot due to deposition of yellow pigment (xantochrome granules), is located in the posterior pole of the human eye starting $0.5 \mathrm{~mm}$ from the optic nerve head (blind spot). Although its diameter is only $6 \mathrm{~mm}$, the macula is the most important part of the eye for contrast discrimination due to the high concentration of cones in this area. The innermost part of the macula is the fovea $(1.85 \mathrm{~mm}$ in diameter), with at its center the foveola (diameter $0.35 \mathrm{~mm}$ ). Outside the fovea is the parafovea (radius 0.5 $\mathrm{mm}$ ), and the perifovea (radius $1.5 \mathrm{~mm}$ ). The retina can be divided (starting from the vitreous) in the neuroretina and the RPE (Fig. 1). The neuro-retina is com-

\footnotetext{
*Correspondence to: Dr. P.T.V.M. de Jong, The Netherlands Ophthalmic Research Institute, Amsterdam, The Netherlands.

Received 17 May 1994; Accepted in revised form 26 October, 1994
} 


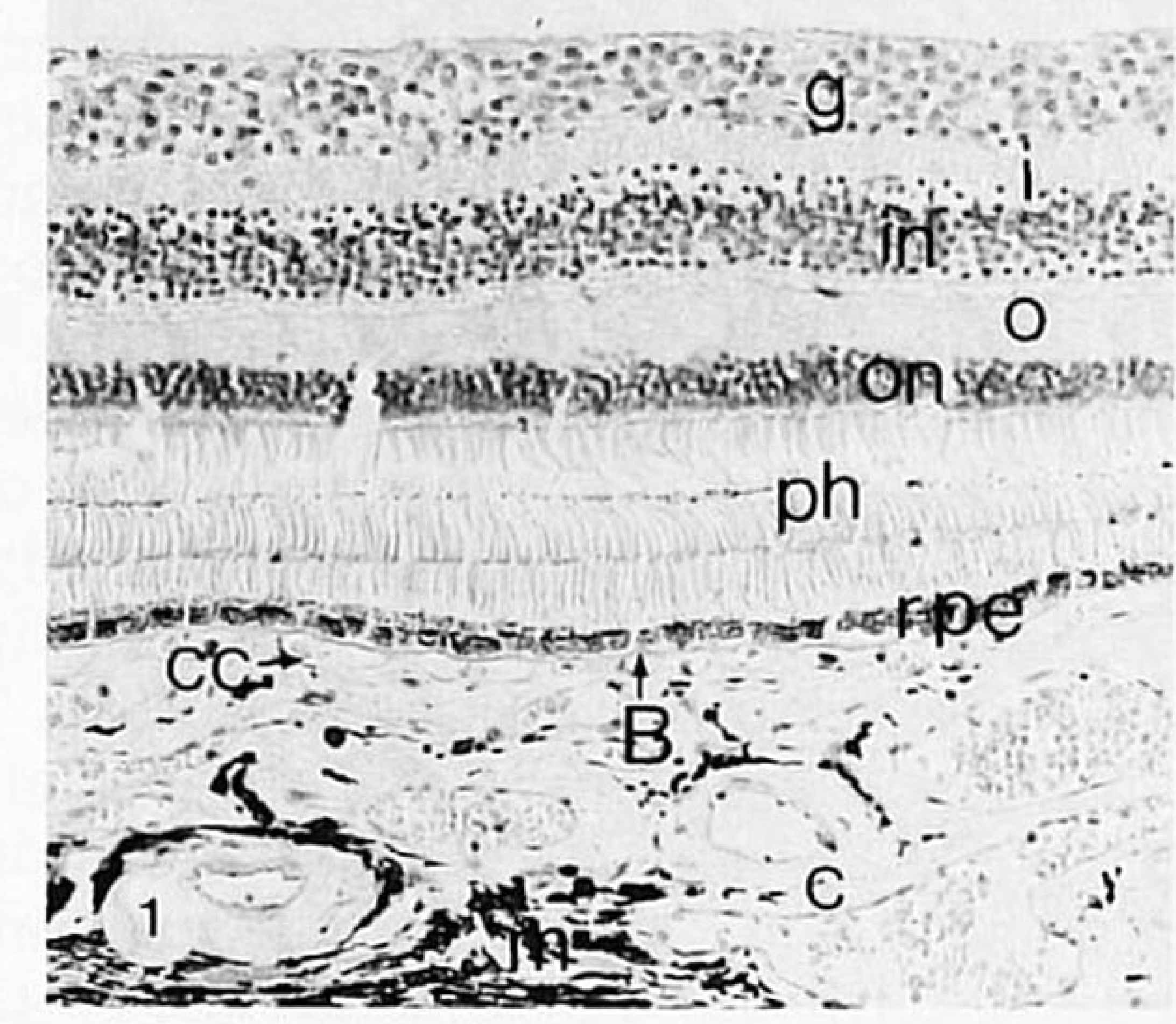

Fig. 1. Light microscopic image of a normal macula. Mayer's hematoxylin, magnification $\times 200$. $g=$ ganglion layer; $\mathrm{i}=$ inner plexiform layer; in = inner nuclear layer; $0=$ outer plexiform layer on $=$ outer nuclear layer; $\mathrm{ph}=$ photoreceptor layer; $\mathrm{rpe}=$ retinal pigment epithelium; $\mathrm{B}=$ Bruch's membrane; $\mathrm{cc}=$ choriocapillaris; $\mathrm{c}=$ choroid; $\mathrm{m}=$ melanocytes.

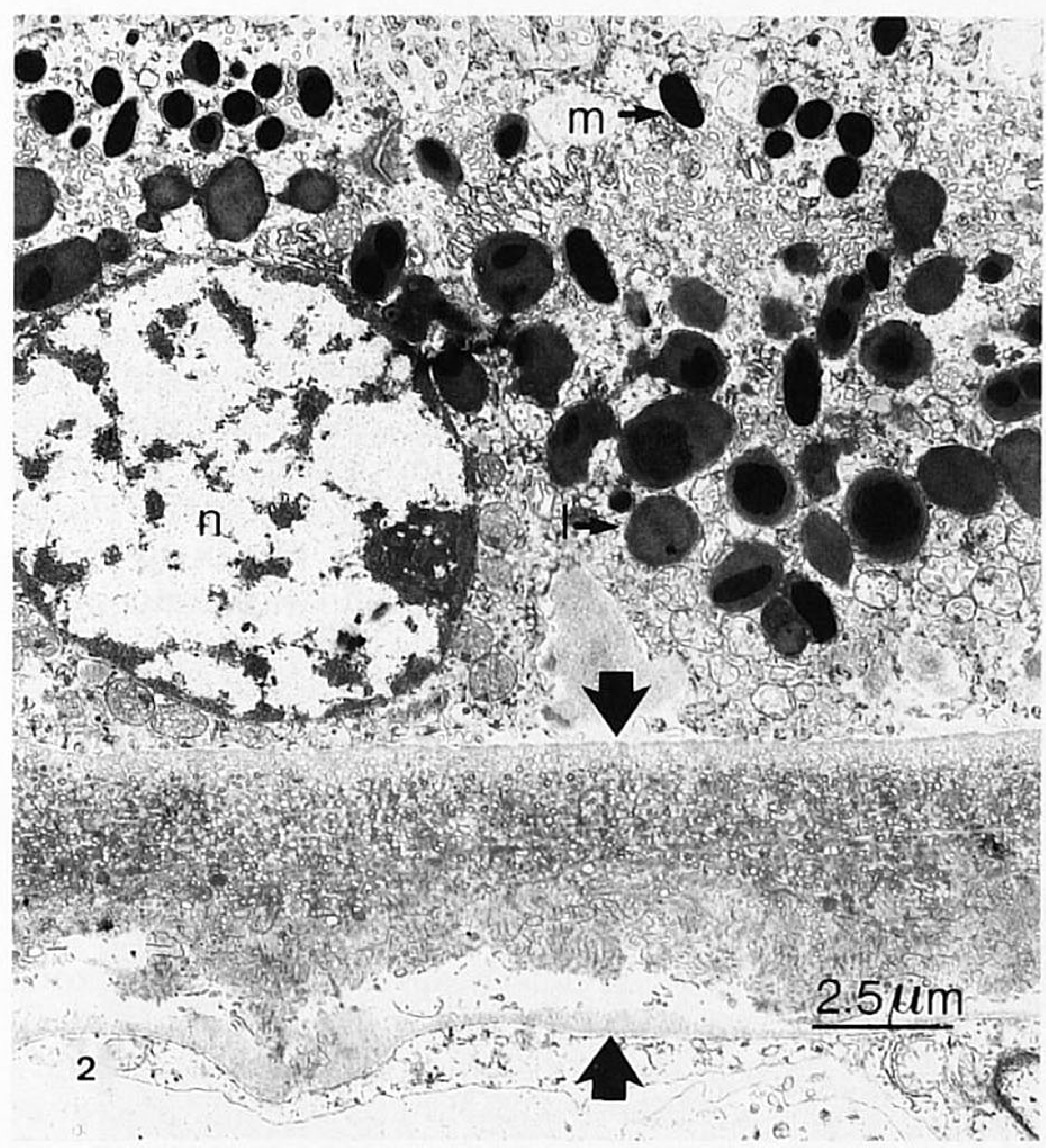

Fig. 2. Electron micrograph of lipofuscin (1) accumulation in a retinal pigment epithelium (RPE) cell. Bruch's membrane (between large arrows) is filled with debris. $\mathrm{m}=$ melanin granule; $\mathrm{n}=$ nucleus of RPE cell.

posed of the inner limiting membrane, nerve fiber layer, ganglion cells, inner plexiform layer, inner nuclear layer, outer plexiform layer, outer nuclear layer, and photoreceptor layer (Fig. 1). External to the RPE lies Bruch's membrane that forms a barrier between the retina and the choriocapillaris (Fig. 1). The choriocapillaris is a thin capillary network closely related to Bruch's membrane, and is the internal part of the choroid, a layer of loose connective tissue with larger blood vessels and melanocytes (Fig. 1). The choriocapillaris is essential for the nutrition of the retina. The outermost layer of the eye is the sclera. Although the architecture of the retina outside the macular region is similar, there are many differences in the individual layers due to the specialized functions of the macula. Whereas the nerve fiber layer in the macula is only a thin layer on top of the ganglion cells, in the peripheral retina it is more prominent. On the other hand the ganglion cell layer is more conspicuous in the macula. A more extensive description can be found in Histology of the Human Eye (Hogan et al., 1971).

\section{AGING CHANGES IN THE NEURO-RETINA AND RETINAL PIGMENT EPITHELIUM}

Like all cells of neural origin, the cells in the retina are post-mitotic and differentiated (Friedman and Tso, 1968). This means that, under normal circumstances, they are unable to regenerate new cells after the loss of old or damaged cells. Therefore, the thickness of the retina decreases with advanced age, due to loss of photoreceptor and ganglion cells (Dorey et al., 1989). The photoreceptor outer segments (Fig. 1) contain stacks of photoreceptor discs that are continuously shedded during the visual cycle.

During life the RPE cells continuously phagocytize the shedded discs. Each RPE cell is in contact with 20-30 photoreceptors, and each photoreceptor discards 30-100 discs/day (Grindle and Marshall, 1978). This results, on average, in a turnover rate of 2,000 discs in the parafovea, 3,500 in the perifovea, and 4,000 discs in the peripheral retina per day, with a photoreceptor/ RPE cell ratio of 24,44 , and 42 , respectively (Hogan, 1972). Photoreceptors are highly susceptible to phototoxic effects of visible and ultraviolet light, due to the large amount of polyunsaturated fatty acids in their densely stacked phospholipid membranes, and it has been recently suggested that rods are more vulnerable to aging changes than are cones (Curcio et al., 1993). Lipid peroxidation in the membranes occurs by free radicals, which are formed by the absorbed radiant energy. These aberrant molecular lipids cannot be digested by the lysosomal enzymes of the RPE cells (Lerman, 1988; Yurchenco and Furthmayr, 1984). However, it is still hypothetical whether lipid peroxidation is important to the development of ARM. The combined action of superoxide dismutase, catalase, and glutathione peroxidase in the RPE cells is one metabolic pathway for protection against oxidative damage. $\mathrm{Al}$ though superoxide dismutase activity shows no correlation with aging and ARM, the activity of catalase decreases significantly with aging and ARM (Liles et al., 1991). This information supports the idea that oxidative damage is of importance in the development of ARM. When the digestion of the shedded discs is incomplete or diminishes, lipofuscin granules (Fig. 2) are formed (Feeney-Burns et al., 1980; Grindle and Marshall, 1978). These granules are considered as residual bodies, which accumulate in the RPE cytoplasm. Lipofuscin is a heterogeneous aggregation of damaged molecules rather than a native product (Yurchenco and Furthmayr, 1984) and is present in all aging species and aging tissues. Like melanin, lipofuscin absorbs radiation from the infrared through the visible into the ultraviolet band, with an increasing efficiency 

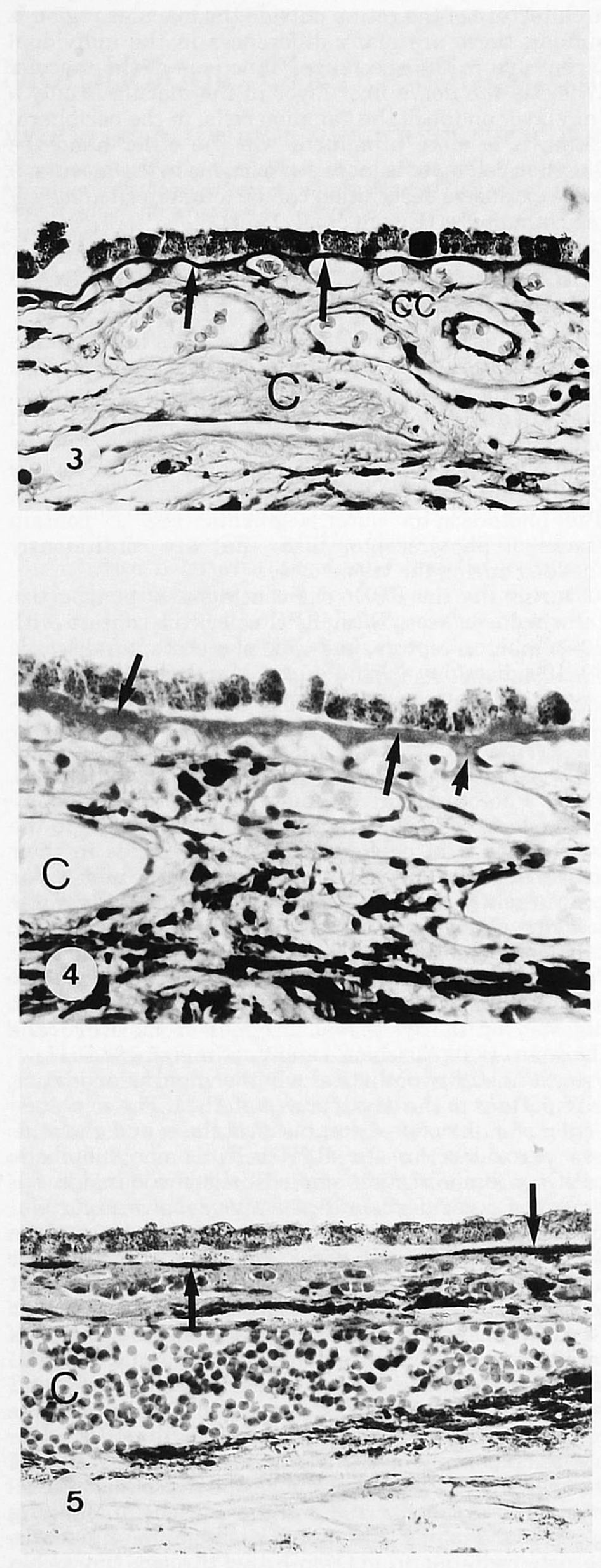

as photon energy increases (Yurchenco and Furthmayr, 1984). There is no evidence that these lipofuscin granules can be extruded from the cytoplasm (Feeney-Burns et al., 1990). The number of lipofuscin granules increases rapidly after birth during the first two decades of life (Wells et al., 1989) especially in the macula, although in the fovea less lipofuscin has been found (Feeney-Burns et al., 1980). Between the ages of 20 and 60 years the amount of lipofuscin is relatively stable, but after the age of 60 years the number of lipofuscin granules increases again (Wells et al., 1989). There is an inverse relationship between the number of lipofuscin granules and the number of melanin granules in the RPE cells of the macula (Feeney-Burns et al., 1980; Feeney-Burns and Ellersieck, 1985; Weiter et al., 1986). The increase in lipofuscin causes a detectable enlargement of the cells during normal aging (Friedman and Tso, 1968; Sarks et al., 1988; Wells et al., 1989). It is hypothetical that the cell metabolism is gradually affected as the cytoplasmic space available to the organelles is reduced (Sarks et al., 1988). The decrease of the number of RPE cells is correlated with the accumulation of lipofuscin (Dorey et al., 1989). The phagocytizing capacity of these cells has to be taken over by neighbouring RPE cells. Subsequently, these cells are flooded by the photoreceptor discs, which have to be digested. Although the enzyme activity of acid phosphatase, and cathepsin D, two lysosomal enzymes responsible for the degradation of ingested photoreceptor outer segment material, increases with increasing age (Boulton et al., 1994), there is a rapid accumulation of lipofuscin in the remaining RPE cells. Consequently, the cell metabolism gets even more affected, resulting in RPE atrophy that might finally lead to AMD (Dorey et al., 1989). However, no correlation has been found between the amount of lipofuscin and the development of AMD, although Weiter et al. (1986) found an increased amount of lipofuscin in two patients with AMD, in comparison with age-matched controls.

\section{AGING CHANGES IN BRUCH'S MEMBRANE}

Bruch's membrane is composed of five layers: the basement membrane of the RPE, the inner collagenous zone (ICZ), the elastic layer, the outer collagenous zone (OCZ), and the basement membrane of the choriocapillaris. With advancing age, the thickness of Bruch's membrane increases in almost all eyes (Ramrattan et al., 1994; Sarks et al., 1988; Sarks, 1976; van der Schaft et al., 1992b). Thus the "normal" structure of Bruch's membrane in older individuals appears to be debrisfilled (Feeney-Burns and Ellersieck, 1985). Because the $\mathrm{RPE}$ cells cannot divide under normal conditions, they

Fig. 3. Light microscopic image of normal Bruch's membrane (arrows). Periodic acid-Schiff reaction, magnification $\times 400$. $\mathrm{C}=$ choroid; $\mathrm{cc}=$ choriocapillaris

Fig. 4. Light microscopic image of diffuse thickening of Bruch's membrane (long arrows). Note the intercapillary pillars (short arrow). Periodic acid-Schiff reaction, magnification $\times 400$. $\mathrm{C}=$ choroid.

Fig. 5. Light microscopic image of calcifications in Bruch's membrane (arrows). Von Kossa stain, magnification $\times 400 . \mathrm{C}=$ large choroidal blood vessel. 


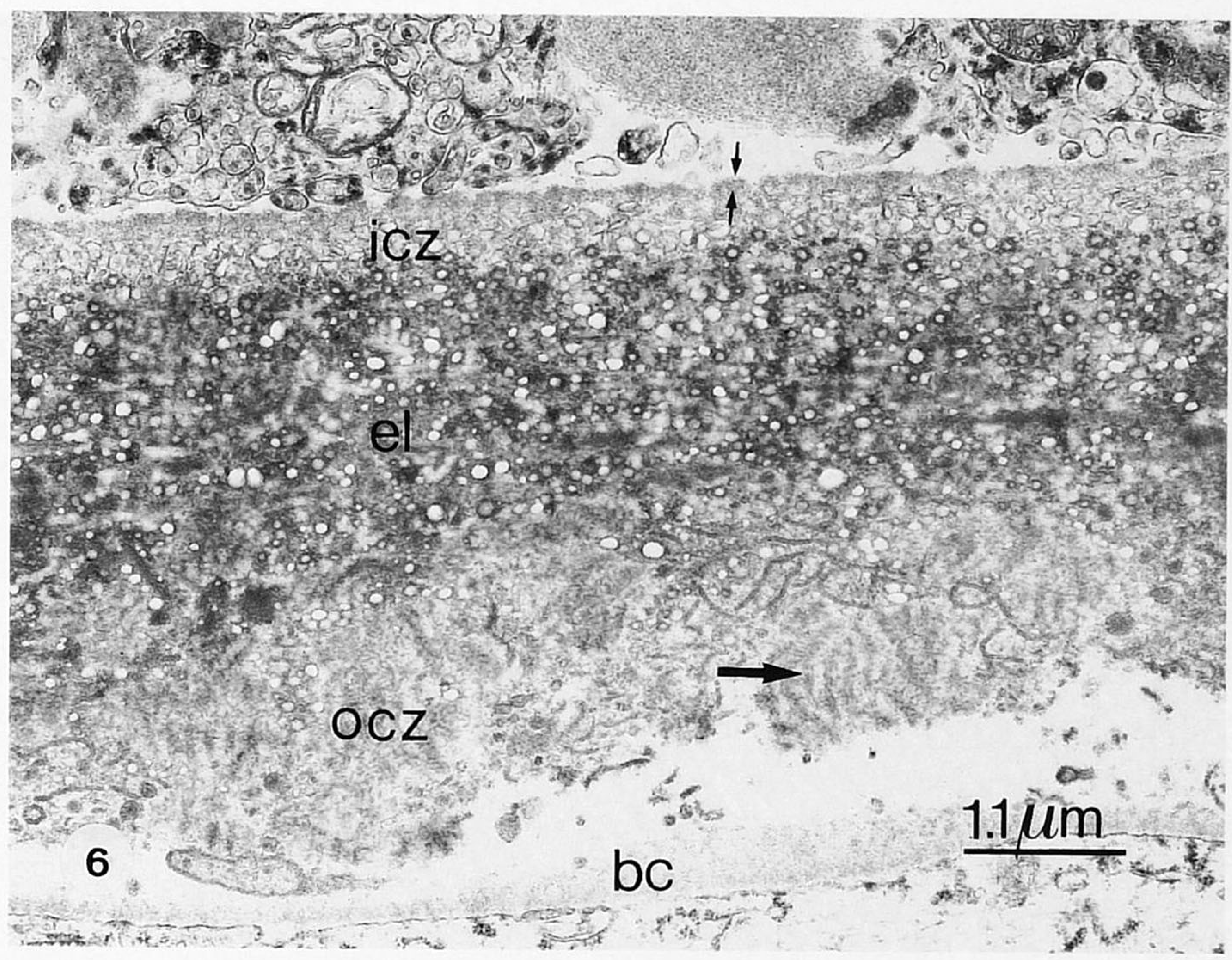

Fig. 6. Electron micrograph of cellular debris in Bruch's membrane. Higher magnification of Figure 2. Note the long spacing collagen (large arrow) in the outer collagenous zone (ocz). The basement membrane of the retinal pigment epithelium is between small arrows. icz = inner collagenous zone; el = elastic lamina; $b c=$ basement membrane of the choriocapillaris.

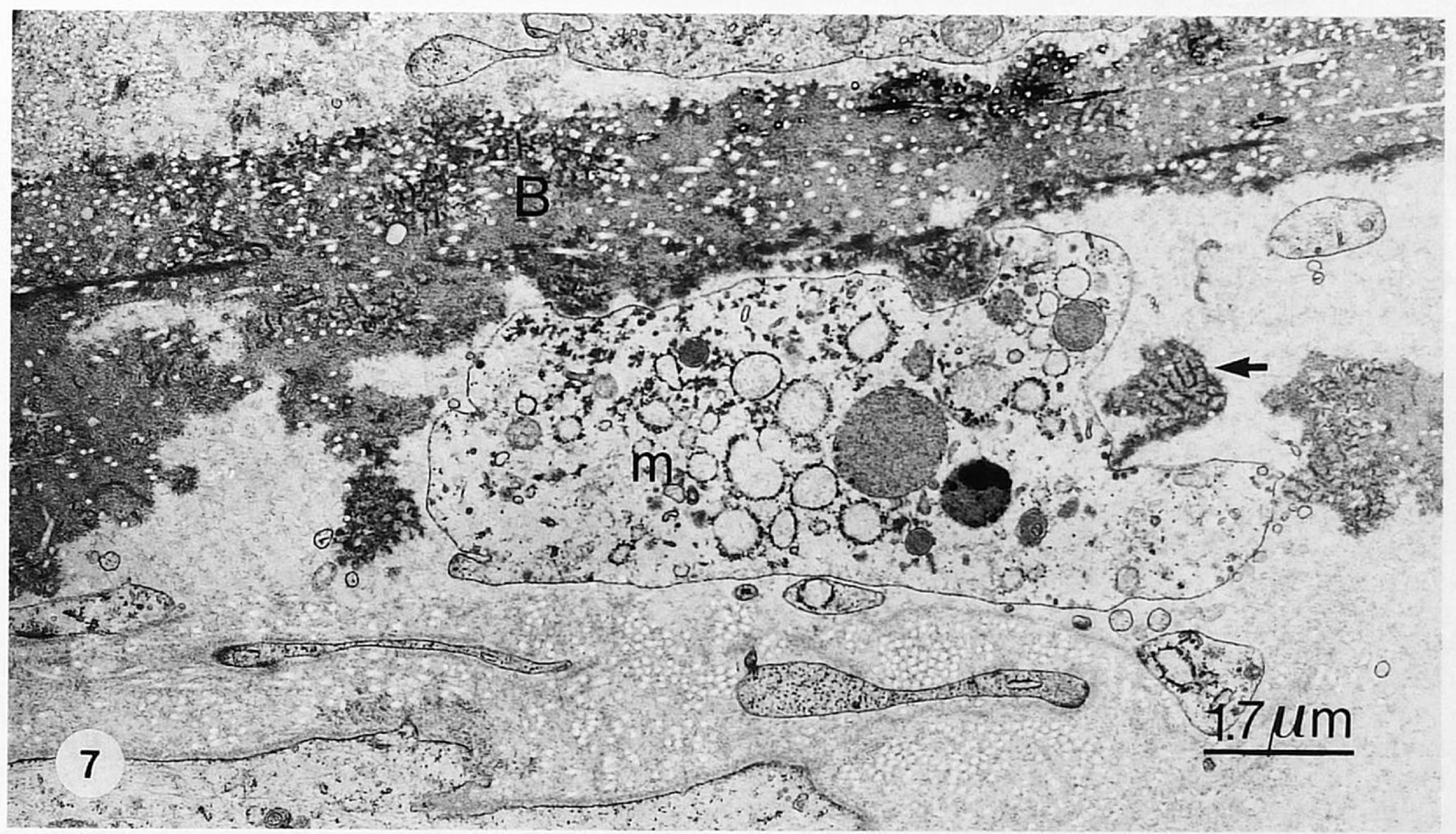

Fig. 7. Electron micrograph of a macrophage $(\mathrm{m})$ beneath Bruch's membrane (B). The macrophage is engulfing debris from Bruch's membrane including long spacing collagen (arrow). 


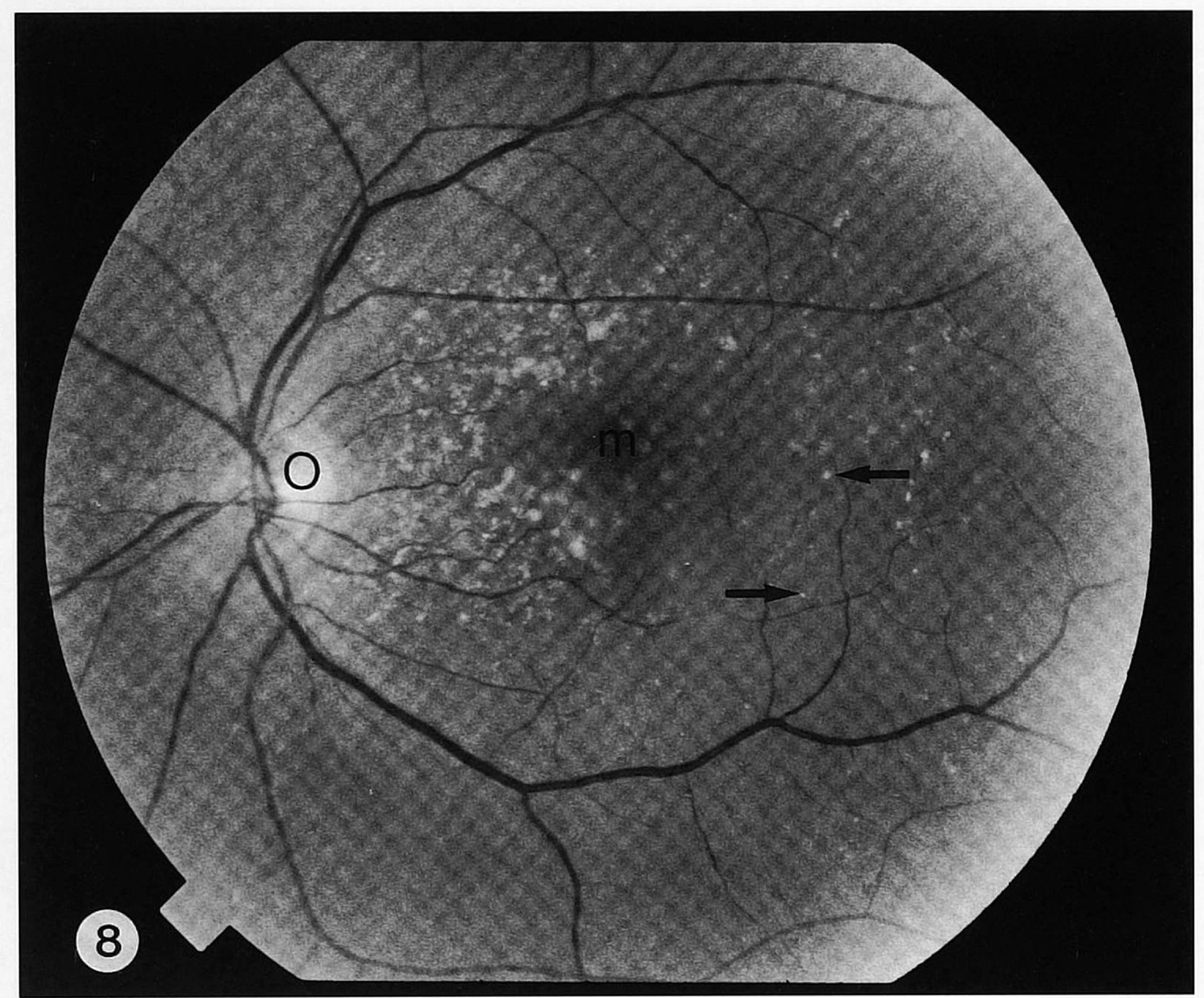

Fig. 8. Multiple small hard drusen (arrows) seen on funduscopic examination as small yellow-white spots. The slightly darker region in the middle of the figure is the macula $(\mathrm{m})$. Note that many of the drusen are melting into each other. $\mathrm{O}=$ optic disc.

must "renew" themselves by autophagy and the subsequent synthesis of new cell organelles (Feeney-Burns and Ellersieck, 1985).

In histological sections Bruch's membrane increases from a thin line in children to a thick membrane in the elderly (Figs. 3 and 4) (Hewitt et al., 1989; Ramrattan et al., 1994; Sarks, 1976; van der Schaft et al., 1992b). In the human macula this thickening is mainly seen in the OCZ, especially between the capillaries of the choriocapillaris, where the so-called intercapillary pillars (Fig. 4) are formed (Killingsworth, 1987; van der Schaft et al., 1992b). In the peripheral retina the age-related thickening is located predominantly in the ICZ (Hewitt et al., 1989). With advancing age, an increasing amount of calcium phosphate is deposited, initially in the elastic lamina of Bruch's membrane, that can easily be demonstrated with the von Kossa stain (Fig. 5) (Davis, 1981; Feeney-Burns and Ellersieck, 1985; van der Schaft et al., 1992b). With special lipid stains (Oil red O and Sudan Black), it has been revealed that above the age of 30 years the amount of neutral lipids and phospholipids increases, which makes the membrane relatively hydrophobic, and thus may form a barrier for the fluid transport from the retina to the choriocapillaris, and vice versa (Bird, 1991; Pauleikhoff et al., 1990c; Sheraidah et al., 1993). However, it has

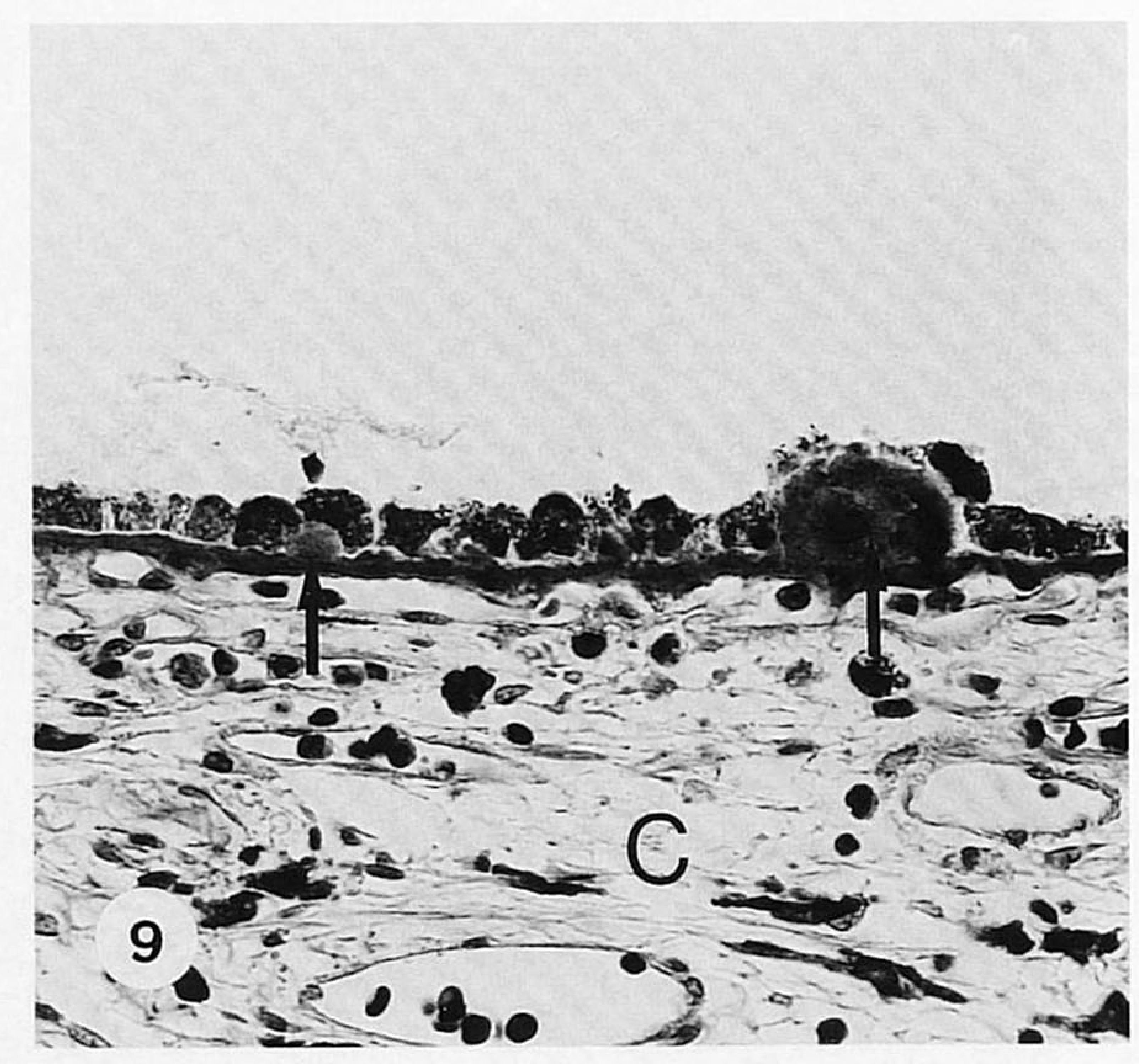

Fig. 9. Light microscopic image of two small hard drusen (arrows) between the basement membrane of the RPE and the inner collagenous zone of Bruch's membrane. Note the hypopigmented RPE cells overlying the biggest drusen. Periodic acid-Schiff reaction, magnification $\times 400 . \mathrm{C}=$ choroid 


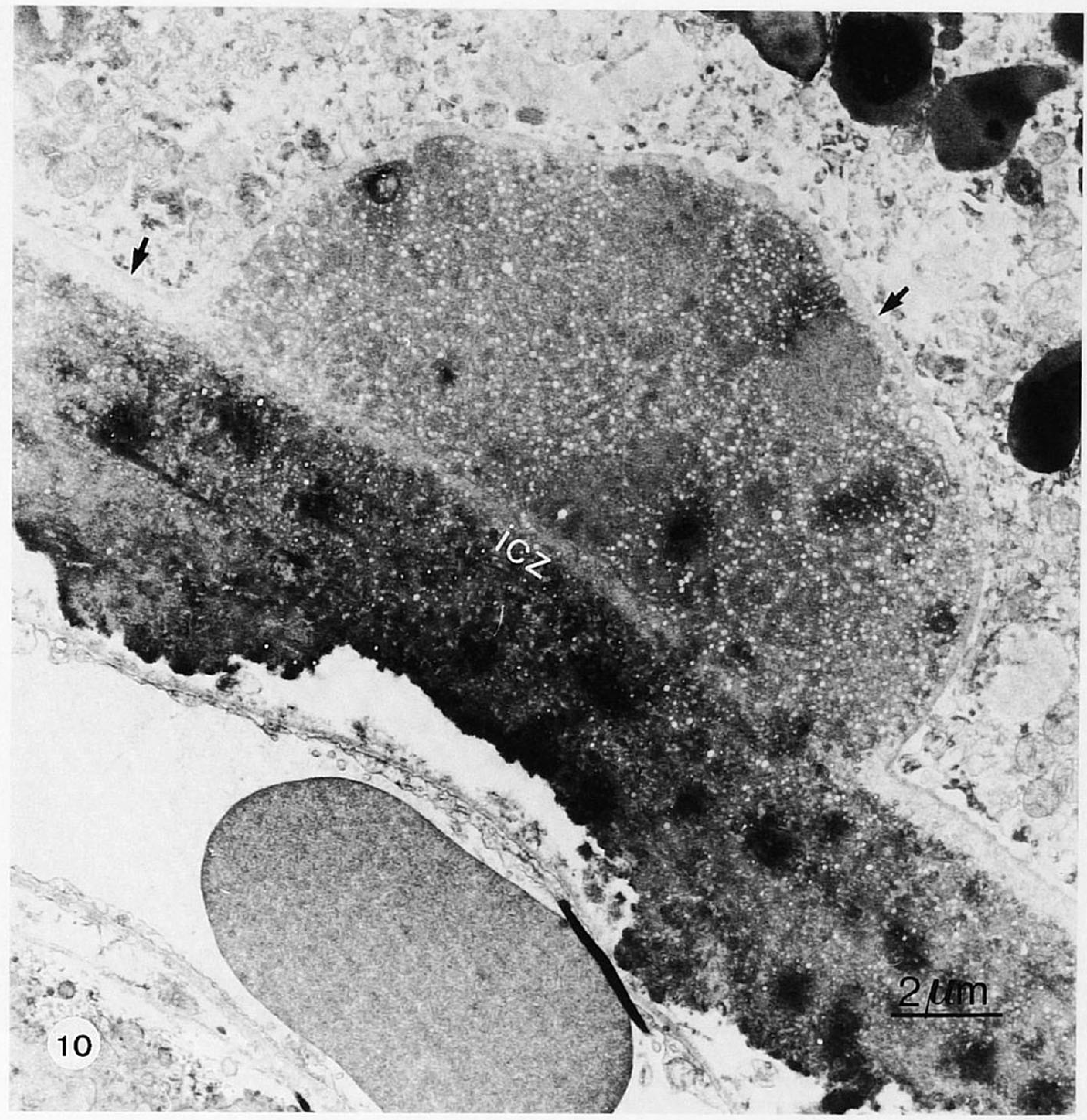

Fig. 10. Electron micrograph of a hard drusen between the basement membrane of the retinal pigment epithelium (arrows) and the inner collagenous zone (icz) of Bruch's membrane.

recently been demonstrated that the permeability of Bruch's membrane decreases in the first 4 decades of life, during which time no increased lipid deposition is established (Moore et al., 1994).

By electron microscopic evaluation the age-related thickening of Bruch's membrane is mainly due to an accumulation of waste products of cellular origin (Figs. 2 and 6 ), consisting of small vesicles, dense granules surrounded by a double membrane, curly membranes and membranous bags, filled with smaller vesicles, and banded material with a periodicity between 100 and $120 \mathrm{~nm}$, which is called long-spacing collagen (LSC, Figs. 2 and 6) (Löffler and Lee, 1986; Nakaizumi, 1964; van der Schaft et al., 1991). These structures might be derived from the RPE cells (Feeney-Burns and Ellersieck, 1985; Killingsworth, 1987; Killingsworth et al., 1990; Pauleikhoff et al., 1990c; Sarks, 1976). Nevertheless, there are considerable differences in the number of chemical elements between the RPE and the deposits in Bruch's membrane, as revealed by electron probe X-ray microanalysis (van der Schaft et al., 1992a). Some subcellular structures seem to be extruded from the basal side of the cells as membranous bags, instead of being digested by the lysosomal enzymes of the RPE

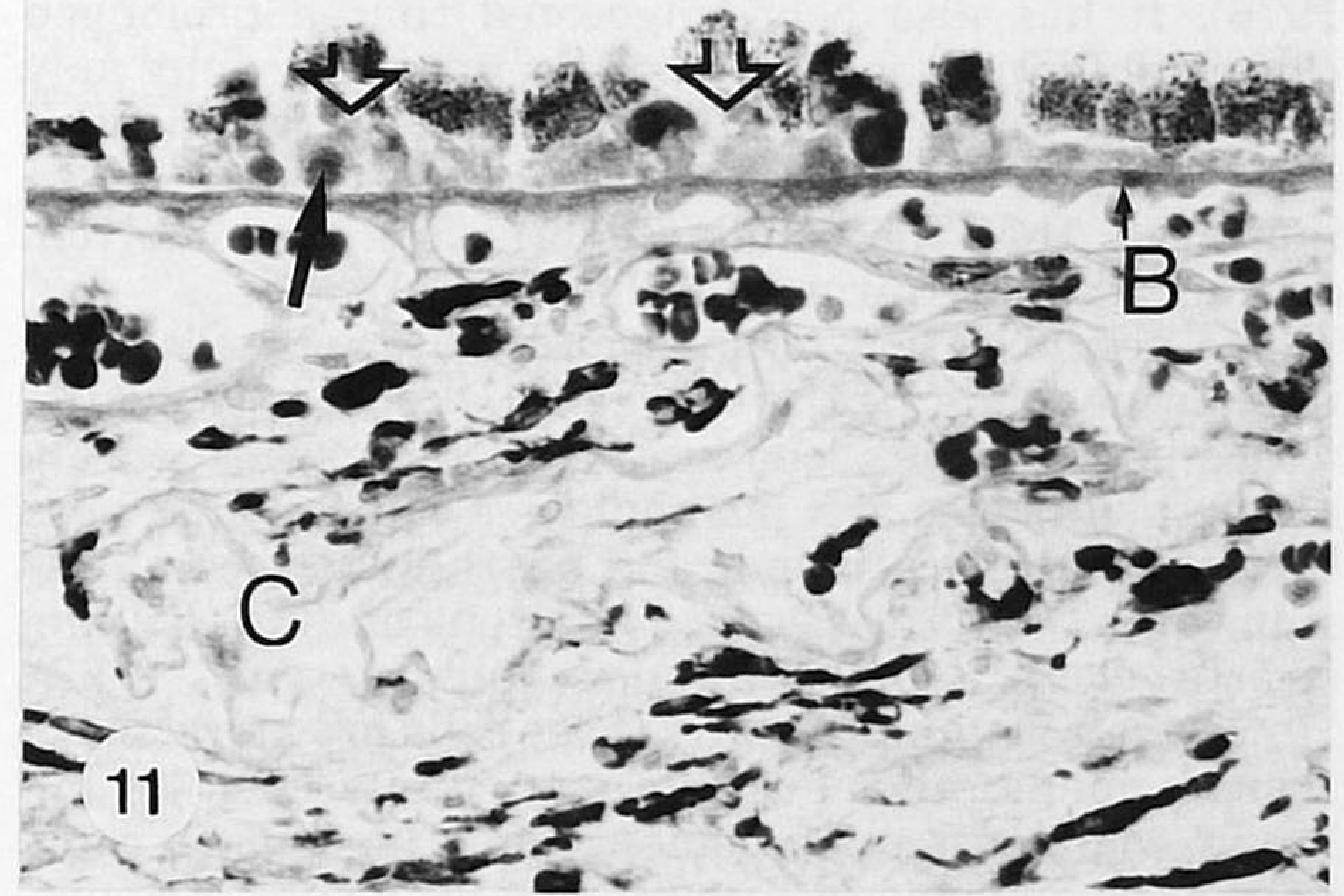

Fig. 11. Light microscopic image of mixed drusen (open arrows). Note the calcifications within the drusen (long arrow). Mallory staining, magnification $\times 400 . \mathrm{B}=$ Bruch's membrane; $\mathrm{C}=$ choroid. 


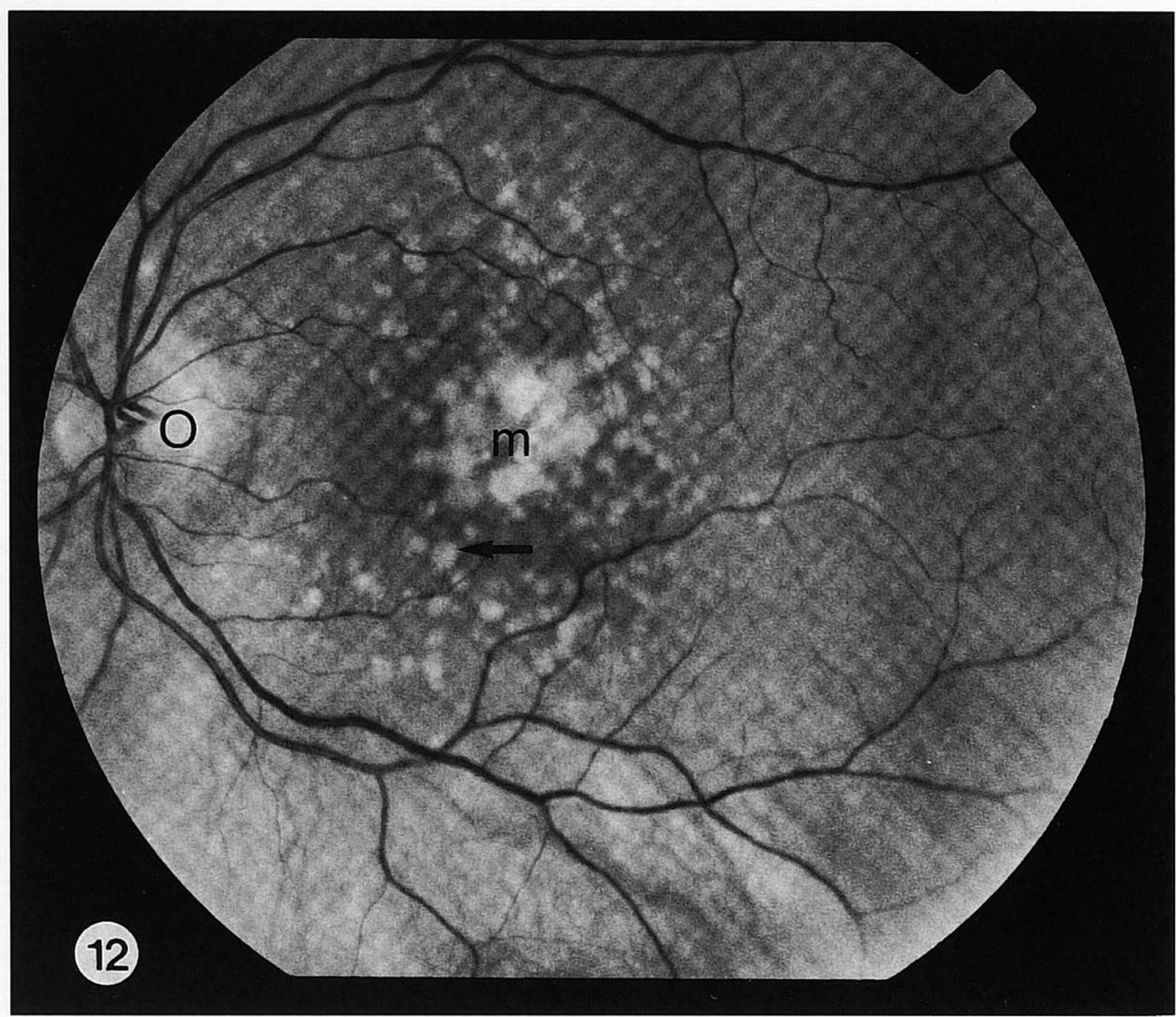

Fig. 12. Multiple soft drusen seen by funduscopic evaluation as large yellow-white spots with indistinct or "soft" borders (arrow). Note the confluent drusen in the macula (m). $\mathrm{O}=$ optic disc.

cells, although physical separation of bodies from the RPE has not been shown until degeneration of these cells was in an advanced stage (Sarks et al., 1988). One hypothesis is, that due to age-related atrophy of the choriocapillaris, this debris cannot be cleared away in due time and accumulates in Bruch's membrane (Sarks, 1976). It has also been suggested that a prolonged choroidal filling phase on fluorescein angiography may be causally related with a diffuse thickening of Bruch's membrane (Pauleikhoff et al., 1990b). There is no indication that the cellular debris is a post mortem artifact (Feeney-Burns and Ellersieck, 1985).

The accumulation of abnormal material in Bruch's membrane might be the cause of the cellular response, which is sometimes seen in ARM (Killingsworth et al., 1990). Leucocytes and macrophages can be found near breaks in Bruch's membrane on the choriocapillaris side (Fig. 7), but are not a consistent finding (Killingsworth et al., 1990; van der Schaft et al., 1993). However, it is unknown why these cells are attracted to Bruch's membrane. Possible attractants such as immune complexes, complement, and fibrinogen could neither be detected in Bruch's membrane nor in deposits like BLD and drusen (see Drusen and Basal Laminar Deposit) in human maculae (van der Schaft et al., 1993).

\section{DRUSEN}

Drusen are located between the RPE basement membrane and the ICZ of Bruch's membrane. They have been described predominantly in the periphery of the eye (Hewitt et al., 1989), especially in the equatorial region (Sarks, 1970), but later investigation has been focussed on drusen in the posterior pole (Green, 1985; Sarks et al., 1980). The origin of drusen has been a source of speculation. It has been postulated that drusen consist of exudative material from the choriocapillaris (Sarks, 1980). Others think that they are comprised of cellular debris from the RPE (Farkas et al., 1971; Green et al., 1985; Ishibashi et al., 1986; Killingsworth et al., 1990). Their element composition on electron-probe X-ray microanalysis gives no clues in this matter (van der Schaft et al., 1992a). The cellular structures, which can be observed within the drusen, are believed to be derived from macrophages (Grindle and Marshall, 1978; Sarks, 1980) or RPE-derived cells (Burns and Feeney-Burns, 1980), although others do not agree with this hypothesis (Ishibashi et al., 1986).

At present there is no satisfactory classification for drusen, which covers all the different clinical and histological features of drusen (Green et al., 1985). Several types of drusen are distinguished in the litera- 
ture (Sarks et al., 1988). These have been given several-often confusing-names for each type of drusen, due to separate lines of approach by clinicians, pathologists, and biochemists. A description of the terminology will be given here.

Small hard drusen are, both on funduscopic and histologic examination, the predominant type of drusen. Funduscopically such drusen appear as small, yellow-white spots surrounded by a slightly darker rim (Fig. 8).

By light microscopic evaluation these drusen are smooth surfaced, globular, or dome-shaped structures between the RPE and Bruch's membrane (Fig. 9). Small hard drusen consist of hyalin material and often contain multiple globular calcifications, lipids, and mucopolysaccharides (Farkas et al., 1971; Ulshafer et al., 1990). That is why they are sometimes also called "crystalline" drusen.

On electron microscopic examination most hard drusen mainly consist of amorphous, finely granular material with the same electron-density as the RPE basement membrane (Fig. 10). Curly membranes and different kinds of vesicles as well as tubular structures can also be found within these drusen (Green et al., 1985). The RPE cells overlying the drusen often seem to be attenuated and hypopigmented, while the laterally located RPE cells are hypertrophic and hyperpigmented (Burns and Feeney-Burns, 1980). This arrangement of the RPE cells explains why these drusen may appear on fundoscopic pictures as small yellow dots surrounded by a slightly darker rim.

Small "hard" drusen are assumed to be low-risk drusen with respect to the development of AMD (Coffey and Brownstein, 1986; Green and Key, 1977; Green et al., 1985; Sarks, 1976) and with respect to a decrease in visual acuity (Hewitt et al., 1989; Leibowitz et al., 1980). They appear histologically in $6.2 \%$ of all eyes with ARM (Green and Enger, 1993), but on fundus transparencies small drusen are visible in $83 \%$ of persons aged 55-64 years (Vinjerling 1995).

Mixed drusen are seen more often with increasing age (Coffey and Brownstein, 1986; Green, 1985; Sarks, 1976), but are also secondary to trauma, inflammatory and other diseases of the eye (Green, 1985). They have, in a confusing way, been called "degenerative drusen," a name not used here because in our opinion all drusen are degenerative. By light microscopic evaluation such drusen are generally larger than the typical hard drusen, and consist partly of hyalin material and partly of coarse granular material. Such drusen often contain many calcium phosphate globules (Fig. 11), although all types of drusen may show calcifications (Green et al., 1985).

Mixed drusen are assumed to be "hard" drusen filled with discharges of membranous debris from degenerating RPE, which have passed the RPE basement membrane (Sarks, 1982; Sarks et al., 1980). In this situation the lateral borders of the drusen have disappeared, but the contents still seem to be separated from each other by an invisible membrane. Ultrastructurally, these drusen are composed of small amounts of amorphous, finely granular material and relatively large amounts of membranous, tubular, and vesicular material (Kenyon et al., 1985).

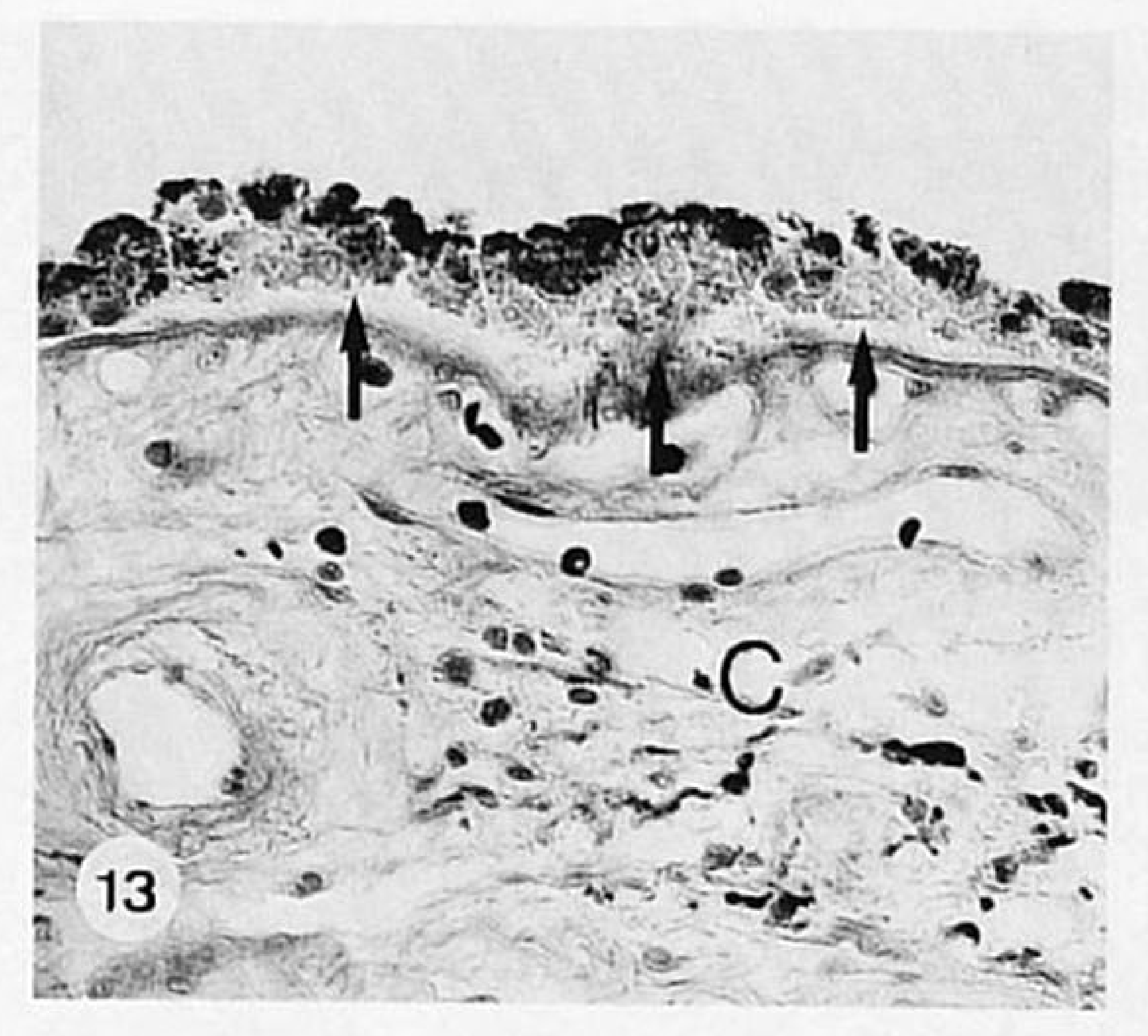

Fig. 13. Light microscopic image of a soft drusen (arrows) between the RPE and Bruch's membrane. The RPE is atrophic. Note the indistinct borders of the drusen. Mallory staining, magnification
$\times 400$. $\mathrm{C}=$ choroid.-

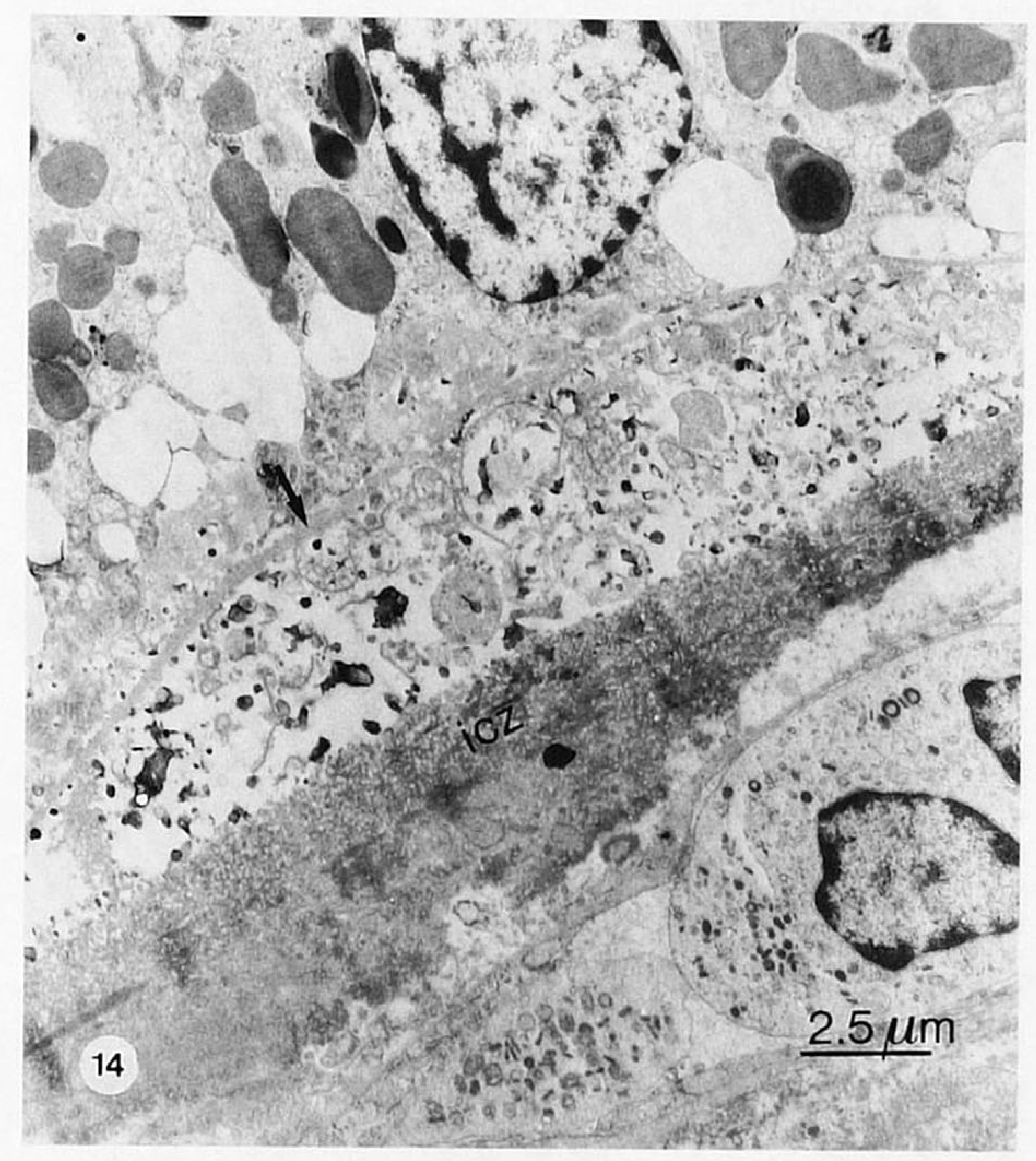

Fig. 14. Electron micrograph of a soft drusen between the basement membrane of the RPE (arrow) and the inner collagenous zone (icz) of Bruch's membrane. Note the difference to the hard drusen in Figure 10.

Soft drusen can develop through the softening of hard drusen (Green et al., 1985), or more commonly by the formation of soft drusen de novo. Soft drusen evolve more rapidly than hard drusen. They tend to become confluent, and separate the RPE basement membrane from the rest of Bruch's membrane over relatively long distances (Green et al., 1985). Probably, soft drusen are a result of RPE dysfunction (Green et al., 1985; Sarks, 1976).

On funduscopic examination such drusen usually appear as large yellow-white spots with indistinct or "soft" borders (Fig. 12). They are preferentially located within the fovea (Sarks et al., 1988) so that RPE and photoreceptor atrophy, developing in relation to soft 

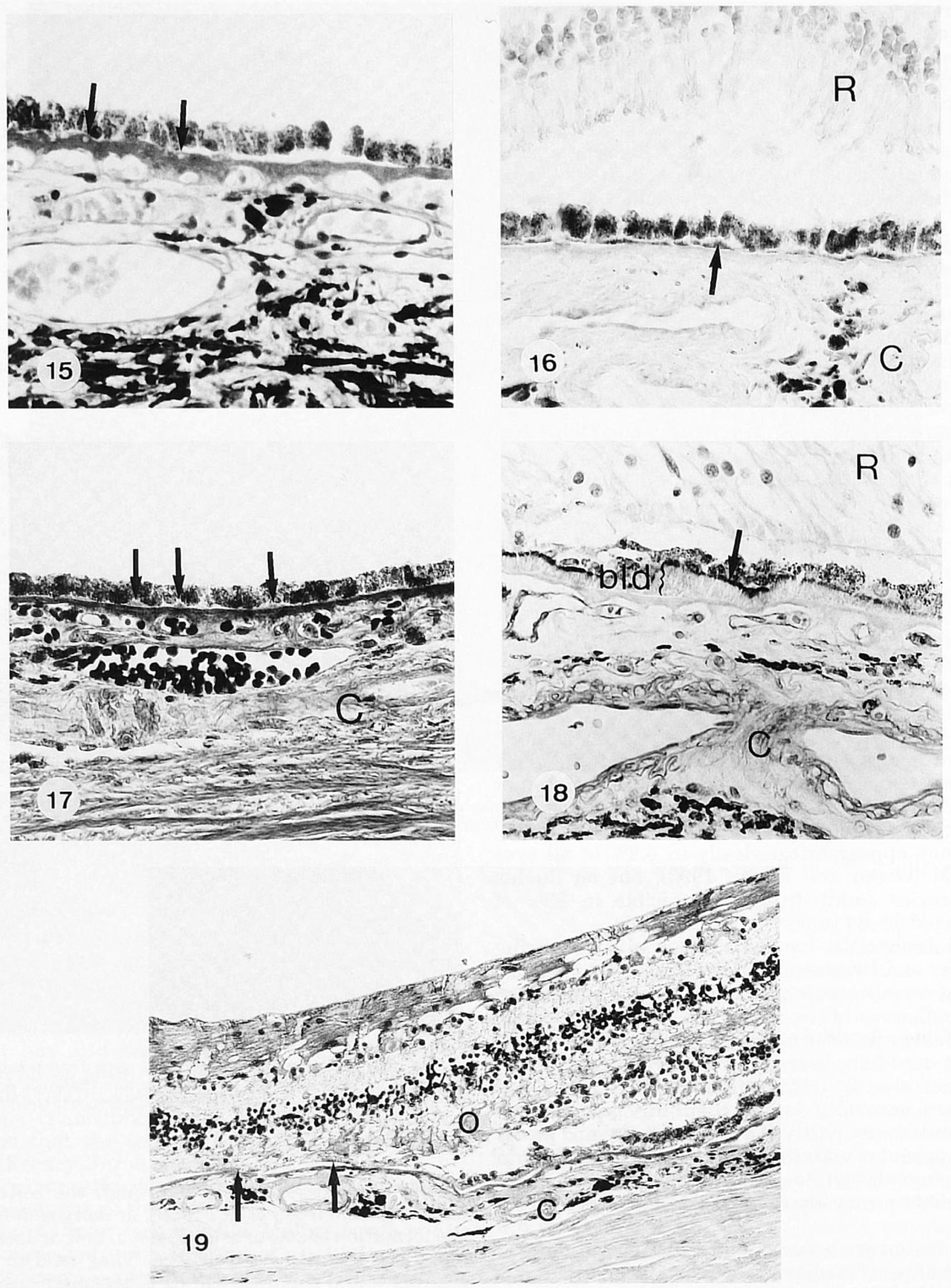

Fig. 15. Light microscopic image of diffuse drusen. Note the small vesicles often seen in this type of drusen (arrows). Periodic acid-Schiff reaction, magnification $\times 400$.

Fig. 16. Light microscopic image of a thin continuous layer (class 2) of basal laminar deposit (BLD, arrow), between the RPE and Bruch's membrane. Stained with dolichos bifloris agglutinin, magnification $\times 400$. $\mathrm{R}=$ photoreceptors of the outer-retina; $\mathrm{C}=$ choroid

Fig. 17. Light microscopic image of small patches of basal laminar deposit (class 1 BLD, arrows). Mallory staining, magnification $\times 400$. $\mathrm{C}=$ choroid .
Fig. 18. Light microscopic image of basal laminar deposit (BLD) class 3. A thick layer of BLD, of at least half the height of the RPE cells, is present (brace), and the RPE on top of the BLD is partially degenerated. A small part of the BLD adjacent to the RPE is stained with polyclonal antibodies against laminin (arrow). Magnification $\times 400 . \mathrm{C}=$ choroid; $\mathrm{R}=$ atrophic outer-retina.

Fig. 19. Light microscopic image of geographic atrophy with RPE and photoreceptor cell degeneration increasing from the right to the left side of figure. On the right part the RPE and outer plexiform layer are still visible; on the left the outer plexiform layer is in direct contact with the persisting BLD (arrows). Mallory staining, magnification $\times 200$. $\mathrm{O}=$ outer plexiform layer; $\mathrm{C}=$ choroid. 

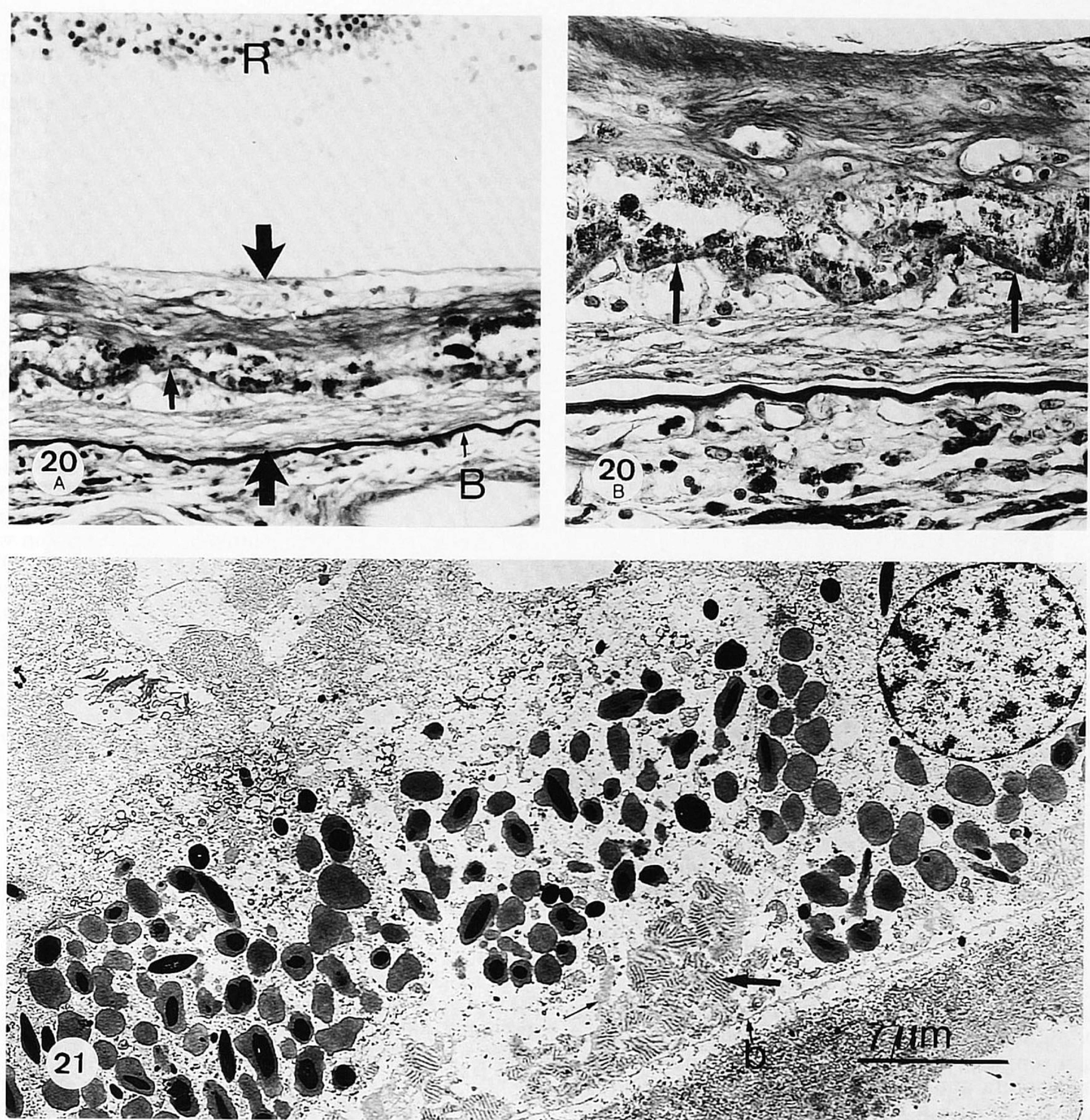

Fig. 20. A: Light microscopic image of disciform macular degeneration (the disciform scar between thick arrows). The retina is totally disorganized. In the middle of the scar are the remnants of the RPE and a layer of BLD-like material (medium arrow). Mallory staining, magnification $\times 200$. $B=$ Bruch's membrane; $R=$ remnants of neuro-retina. B: Same macula with higher magnification $(\times 400)$. Note the BLD-like material in the middle of the scar (arrows). The staining properties and density of this material are the same as those of BLD.

drusen, will start closer to the foveola. Due to their sloping edges, soft drusen often cannot be distinguished from small serous RPE detachments on funduscopic pictures (Green et al., 1985; Kenyon et al., 1985), and this may create difficulties in classification and treatment of these detachments.

On light microscopic examination soft drusen appear as large drusen, with sloping edges, and often seem to be empty or to contain pale staining membranous or fibrillar material (Fig. 13) (Sarks, 1980). The overlying RPE is attenuated or atrophic (Fig. 13). Ultrastructurally, soft drusen are composed of double-layered coiled membranes, with some amorphous material and calcifications (Fig. 14) (Killingsworth et al., 1990). In most eyes with soft drusen, BLD is also found in the same area (Green et al., 1985; Lewis et al., 1986).

Clinically, eyes with confluent soft drusen are at high risk for subretinal neovascularization and geographic 


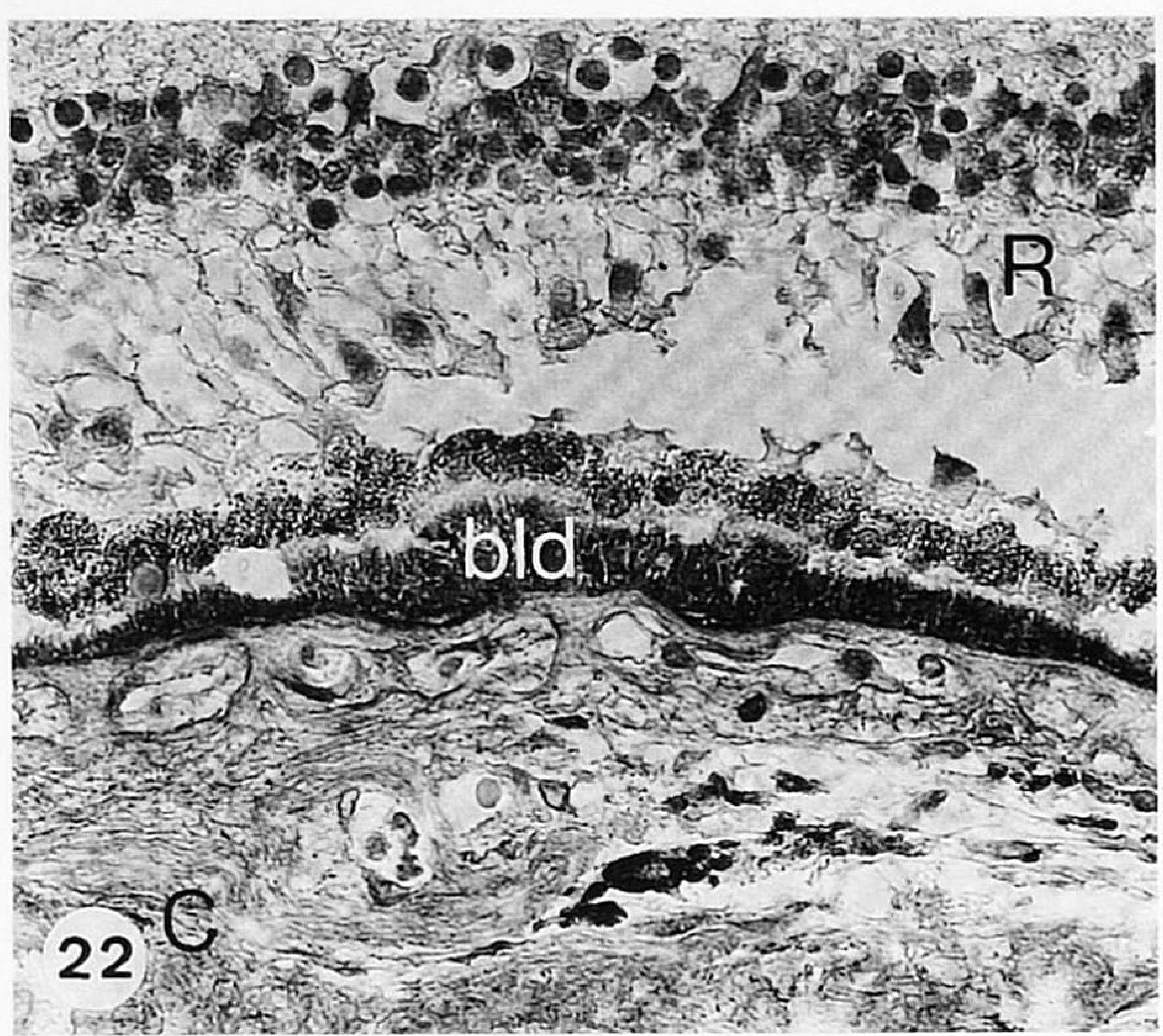

Fig. 22. Light microscopic image of class 3 basal laminar deposit BLD) stained with the lectin dolichos bifloris agglutinin. Note that approximately $90 \%$ of the BLD is stained. Magnification $\times 400$. $\mathrm{C}=$ choroid; $\mathrm{R}=$ outer-retina.

atrophy, and are thus called "high-risk" drusen (Bressler et al., 1989; Green et al., 1985; Sarks, 1980, 1982).

Diffuse drusen is a histopathologic designation for a diffuse thickening of the inner aspect of Bruch's membrane, and is commonly observed in eyes of older persons (Fig. 15) (Kenyon et al., 1985). On ophthalmoscopic examination these drusen cannot be differentiated from continuous soft drusen, or small RPE detachments. Ultrastructural studies have revealed the presence of vesicles, electron-dense particles, fibrils and clusters of LSC (Coffey and Brownstein, 1986; Green, 1985; Green and Key, 1977; Green et al., 1985; Tso, 1985).

The chemical composition of drusen, especially the lipid content, is assumed to be important in the development of ARM (Bird, 1992; Sheraidah et al., 1993). Drusen contain phospholipids or neutral lipids, which are hydrophilic and hydrophobic, respectively (Pauleikhoff et al., 1992a). If drusen consist of neutral lipids, they confer hydrophobic properties, which could hypothetically hamper the diffusion of water and watersoluble molecules through Bruch's membrane (Bird and Marshall, 1986). This hydrophobicity causes hypofluorescence on fluorescein angiography, and is correlated with RPE detachment (Pauleikhoff et al., 1990a, 1992b).

Drusen can be seen in the eyes of 26 to $85 \%$ of people above the age of 30 years (Bressler et al., 1989; Coffey and Brownstein, 1986; Leibowitz et al., 1980; van der Schaft et al., 1992b; Vingerling et al., 1994). There is no preference for the left or right eye (Coffey and Brownstein, 1986; Lewis et al., 1986; Vinding, 1989) and there is no predilection for males or females (Lewis et al., 1986), but drusen are seen more often in whites than in blacks on funduscopic pictures. Commonly, drusen are thought to be associated with ARM. However, only $0.5-2 \%$ of the population will finally develop AMD, despite the high prevalence of drusen (Green et al., 1985; Vingerling et al., 1994).

\section{BASAL LAMINAR DEPOSIT}

In the eyes of the elderly and even in $55 \%$ of the eyes with ARM (Green and Enger, 1993), extracellular deposits have been found between the RPE and its basement membrane (Fig. 16), which have been called "basal laminar deposit(s)" (BLD) (Green and Enger, 1993; Sarks et al., 1988; van der Schaft et al., 1992b), "basal linear deposit(s)" (Löffler and Lee, 1986; Sarks, 1976) or "linear basal deposits" (Feeney-Burns and Ellersieck, 1985). BLD has been found predominantly in the posterior pole of the eye (Lewis et al., 1986; Sarks, 1973). Although these deposits have only been described histologically in enucleated eyes, it has been proven that it is not a post mortem artifact (Garron et al., 1958; Weiter et al., 1985). Due to the localization of $\mathrm{BLD}$, and the basement membrane materials continuously produced by the RPE, it seems likely that BLD is derived from excessive basement membrane materials.

By funduscopic evaluation the presence of BLD is not recognizable as such. In the past, a case report has been published describing a patient with multiple confluent soft drusen, which after histological examination were determined as not being drusen (Frank et al., 1973). Unfortunately, BLD was not recognized as an entity, by that time. Like drusen, BLD should be indirectly visible due to the atrophy and degeneration of the overlying $\mathrm{RPE}$. Large amounts of BLD may be recognizable as a fine mottling of the RPE at an early stage of geographic atrophy. In our opinion BLD is probably recognized as soft drusen with fluorescein angiography, because of its extensive spread and indistinct borders.

The development of BLD beneath the RPE appears to be a reliable histological criterion for the degree of degeneration of the overlying RPE cells (Sarks, 1976). Consequently, maculae with early stages of ARM are sometimes histologically classified, in class 0 to class 3 BLD (corresponding with group I to IV by Sarks, 1976), according to the appearance of this deposit (van der Schaft et al., 1992b).

In BLD class 0 , no BLD is present. Small patches of BLD (class 1, Fig. 17) under a few RPE cells will probably not disturb fundus pigmentation. The photoreceptors are unaffected. Class 1 BLD is not considered to be ARM. With increasing age, however, these deposits become larger and form a thin continuous layer (BLD class 2, Fig. 16). Loss of photoreceptors is mild, and on ophthalmoscopic examination hypopigmentation or hyperpigmentation can be seen, due to accompanying RPE changes.

In a more advanced stage (BLD class 3 , Fig. 18) a thick continuous layer of BLD is seen, which separates the RPE from the inner layer of Bruch's membrane. The overlying RPE becomes elevated, and more irregular in shape. There is sometimes a migration of solitary, hypertrophied RPE cells between the photoreceptors. Loss of photoreceptors becomes more apparent.

At a later stage, in eyes with a thick layer of BLD, the RPE cells become depigmented and atrophic, finally resulting in the disappearance of the RPE cells and the accompanying photoreceptors. The BLD generally remains present after the RPE has disappeared (Sarks, 1976). This is called the atrophic type of AMD, or geographic atrophy (Fig. 19). The fall out of photoreceptors seems secondary to changes in, and beneath the 


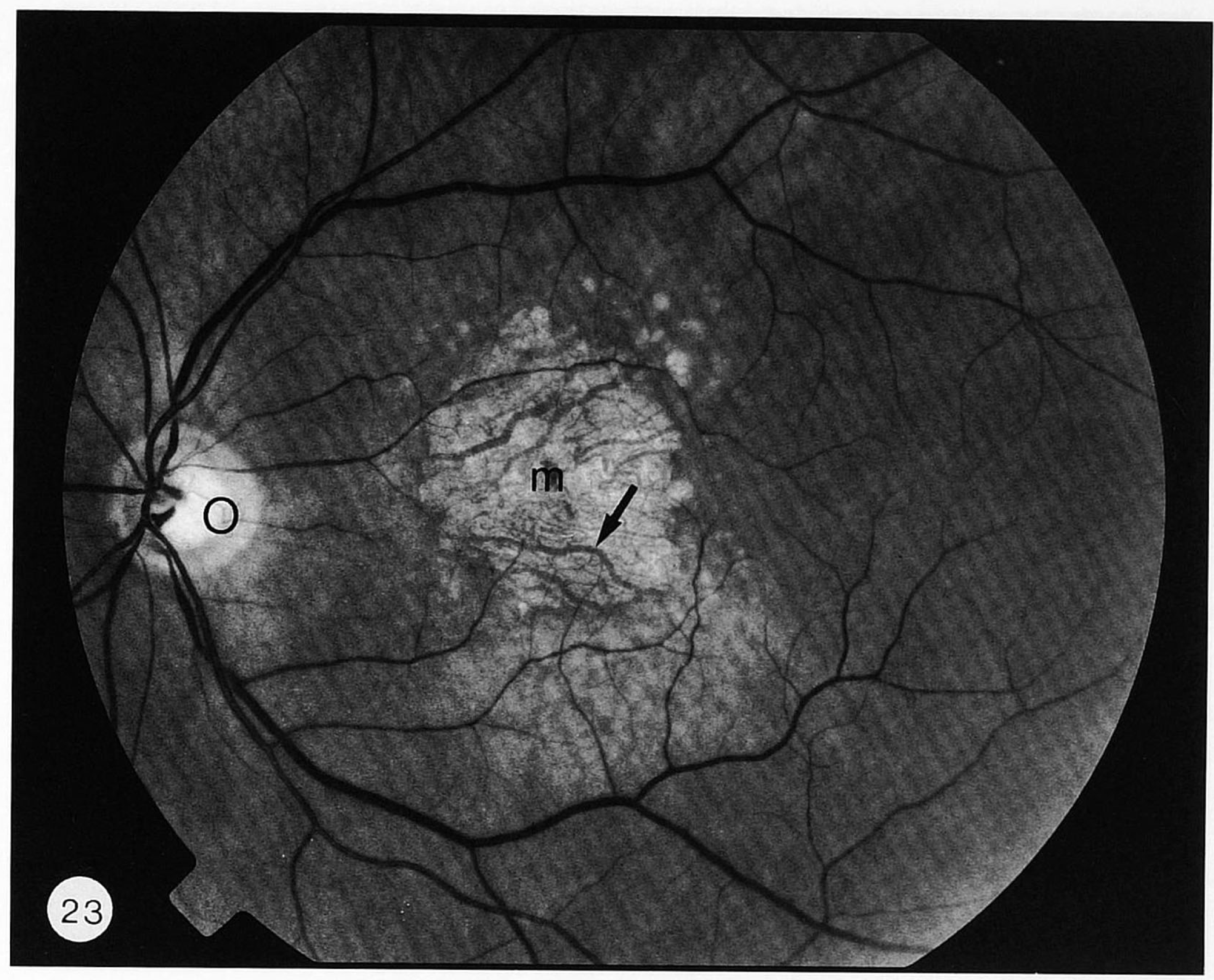

Fig. 23. Funduscopical image of geographic atrophy in the macular area. The vessels of the choroid (arrow) become visible because of the atrophy of the retinal pigment epithelium and neuro-retina. Note the soft drusen upper temporal to the macula, where the choroidal vessels are invisible. $\mathrm{O}=$ optic disc; $\mathrm{m}=$ macula.

RPE. In eyes with the neovascular type of AMD, capillaries are described coursing from the choriocapillaris through breaks in Bruch's membrane and the BLD, without a previous detachment of the RPE, which is commonly associated with neovascularization. This neovascular stage often leads to the formation of a fibrovascular scar (Junius-Kuhnt) in which BLD-like material is incorporated (Fig. 20A,B).

It has been proven by immunohistochemistry that a small part of BLD adjacent to the RPE contains collagen type-IV and laminin (Fig. 18) (Marshall et al., 1992; van der Schaft et al., 1994). However, the main part of BLD consists of carbohydrate structures, most likely part of glycoproteins, which differ from the carbohydrate structures on laminin and collagen type IV (Fig. 22) (Kliffen et al., 1994; Kliffen et al., 1995). Furthermore, chondroitin sulfate, and heparan sulfate have been identified in BLD (Kliffen et al., 1996). A specific carbohydrate (GalNAc) that binds to the lectin Dolichos Bifloris Agglutinin, and that normally is not present in the human macula was also found in BLD (Fig. 22) (Kliffen et al., 1994). Because drusen do not stain with Dolichos Bifloris Agglutinin, this lectin can be used for discrimination between BLD and drusen on light micro- scopic examination (Kliffen et al., 1994). By electron microscopic evaluation, BLD shows similarity with LSC, and a homogeneous material with the same electron density as basement membranes (Fig. 21) (Löffler and Lee, 1986; van der Schaft et al., 1991). Interestingly, LSC is only rarely found within drusen (Kenyon et al., 1985). However, LSC has been found in other parts of the human eye, including the outer and inner collagenous zone of Bruch's membrane, as well as in other tissues, e.g., heart and skin (van der Schaft et al., 1991).

The exact pathogenesis of BLD is unknown, and the importance of BLD in the development of ARM is uncertain (Bird, 1991; Löffler and Lee, 1986), although some authors are convinced of the fact that the presence of BLD is positively correlated with the development of ARM (Feeney-Burns and Ellersieck, 1985; Sarks, 1976). BLD class 1 will probably not disturb fundus pigmentation, nor does it influence visual acuity (Sarks, 1976). In BLD class 2 the most common visual acuity measured was between $5 / 10$ and $6 / 10$ (Sarks et al., 1988; Sarks, 1976). In eyes with BLD class 3 vision was markedly decreased with an average visual acuity of $3 / 10$ (Sarks, 1976). 


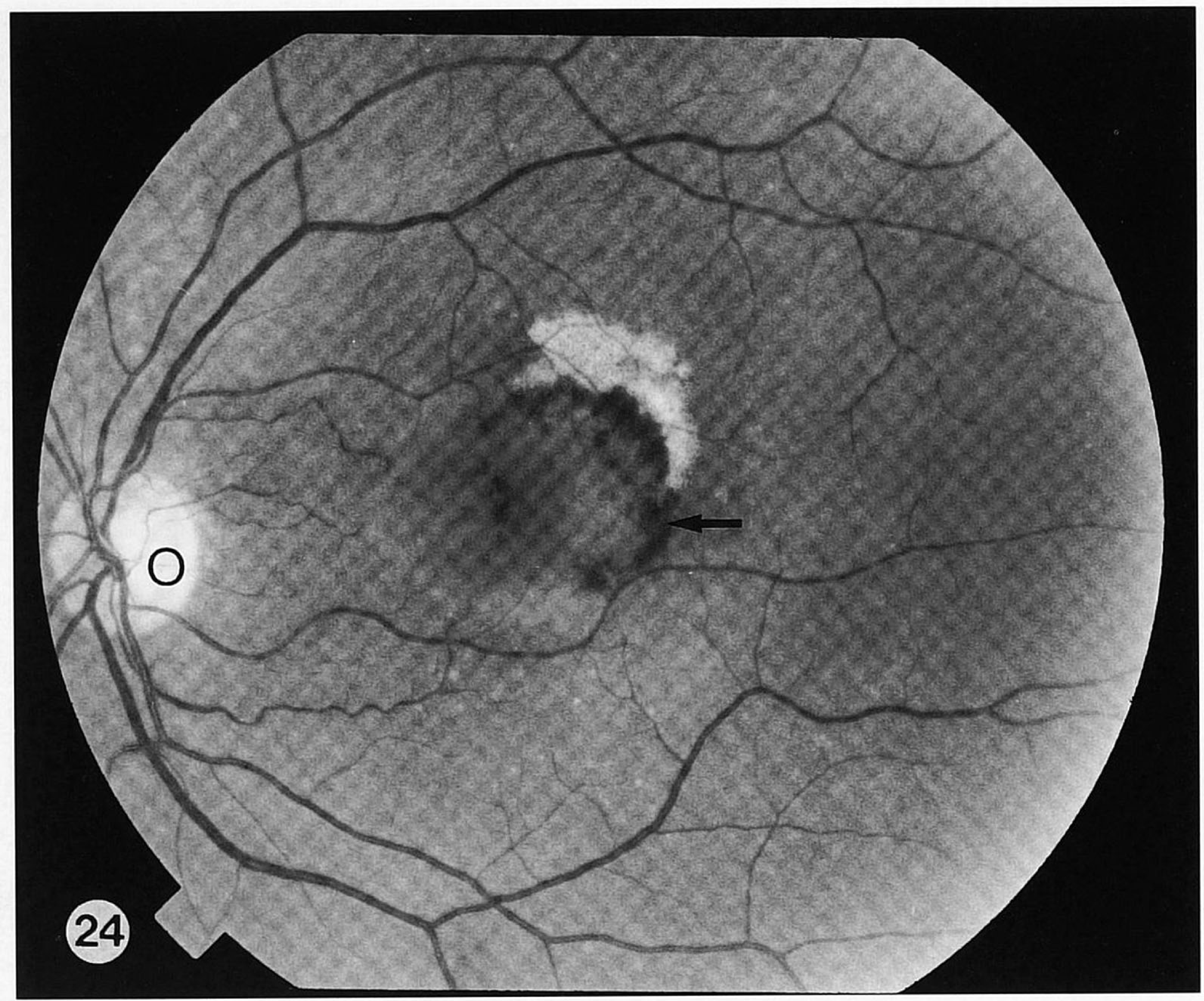

Fig. 24. Funduscopical image of hemorrhage (arrow) from neovascular membrane in the macula. The white rim adjacent to the hemorrhage is either a hard exudate or old blood. $\mathrm{O}=$ optic disc.

\section{AGING CHANGES IN THE CHORIOCAPILLARIS}

In eyes with ARM, changes in the structure of the capillary network (Fryczkowski et al., 1989) and atrophy of the choriocapillaris and choroid can be found (Feeney-Burns et al., 1990; Ramrattan et al., 1994; Tso and Friedman, 1967). Recently, a significant decrease of the capillary density in ARM has been reported (Ramrattan et al., 1994). Once the lumina of the choriocapillaris are obliterated, the intercapillary pillars become eroded by cellular activity (Sarks et al., 1988). The relative ischemia might explain the development of chorioretinal vascular anastomoses in AMD (Fryczkowski et al., 1989), but the exact mechanism of this, and of the centripetal growth of the neovascular subretinal membranes towards the fovea, is unknown.

The RPE cells are known to produce vascular stimulating as well as inhibiting factors, which can act on the choriocapillaris (Campochiaro et al., 1986; Glaser et al., 1985; Korte et al., 1984). Experimental damage of the RPE induced atrophy of the choriocapillaris (Korte et al., 1984). In other experiments, in which a slow degeneration of the RPE was induced, neovascularization was seen (Zrenner, 1990). It is thought that in ARM

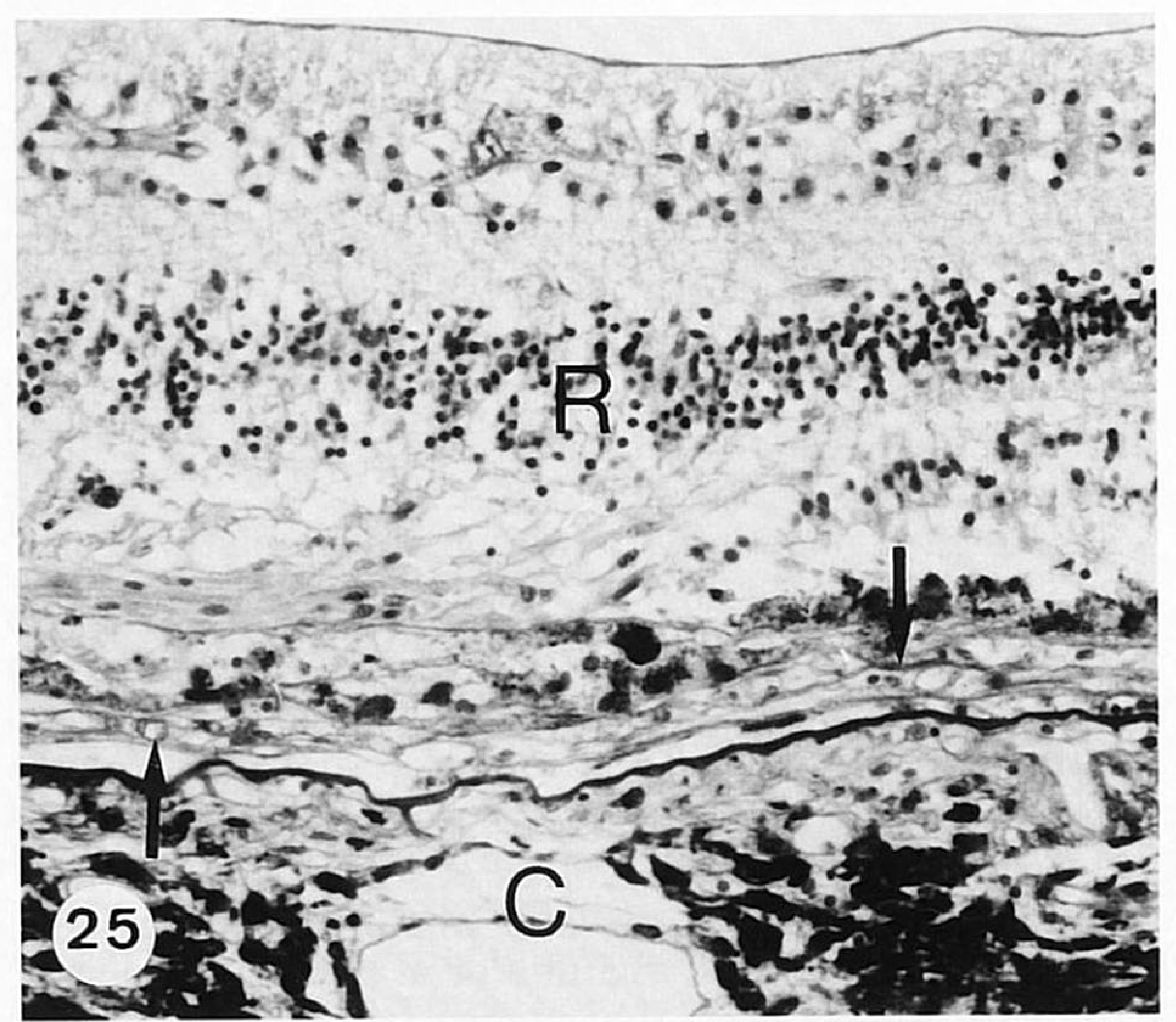

Fig. 25. Light microscopic image of subretinal neovascularization. Note the blood vessels (arrows) between the remains of the RPE and Bruch's membrane. Mallory staining, magnification $\times 200$. $\mathrm{C}=$ choroid; $\mathrm{R}=$ neuro-retina 


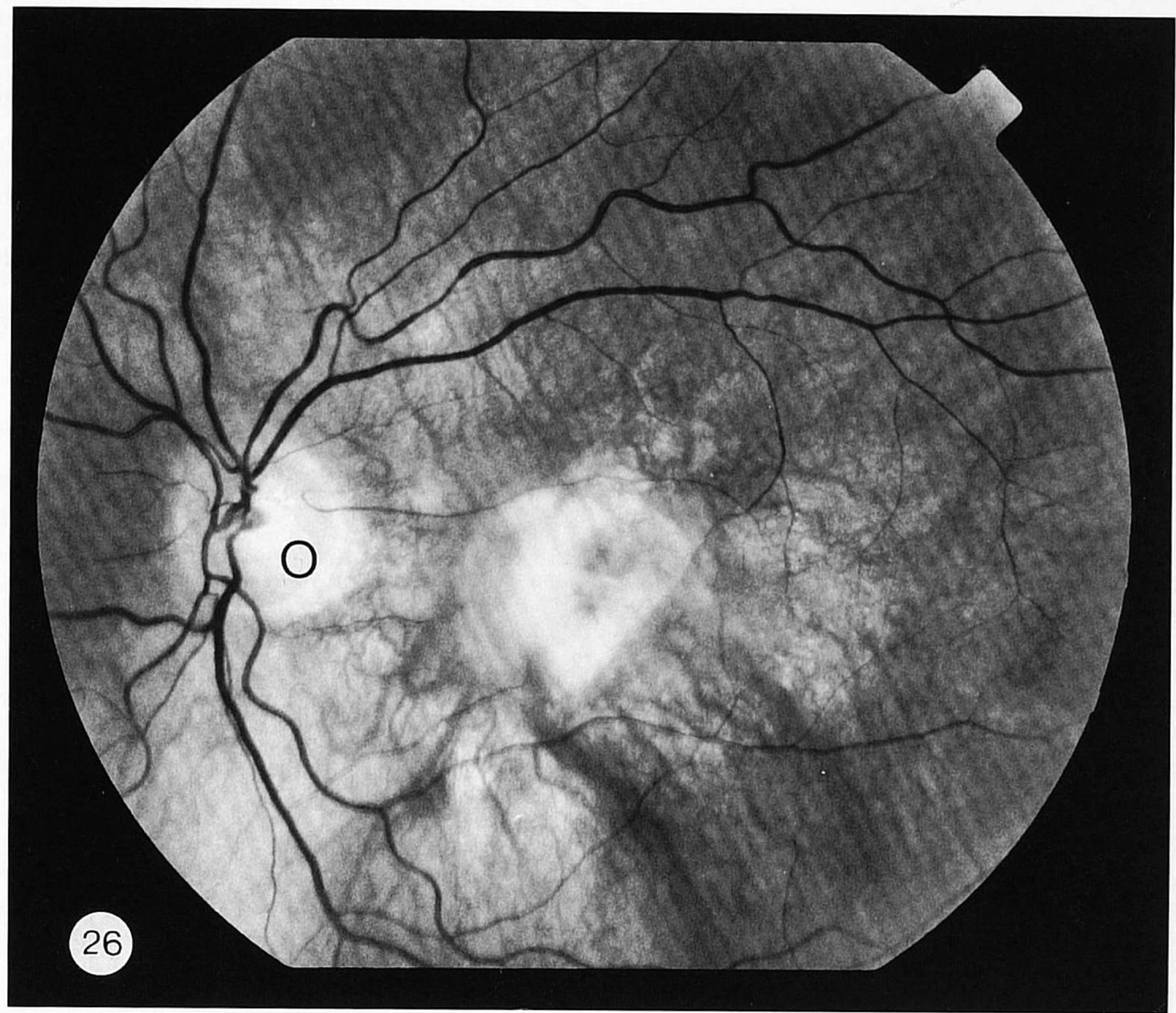

Fig. 26. Funduscopical image of a large disciform scar in the macular area. In contrast with geographic atrophy no choroidal vessels are visible within the scar. $\mathrm{O}=$ optic disc.

the interaction between the RPE and the choriocapillaris is disturbed (Hogan, 1972). However, it is still uncertain whether the changes in the choriocapillaris are secondary to other changes in the macula, or whether this is one of the initiating factors of ARM (Delaney and Oates, 1982; Tso and Friedman, 1967).

\section{GEOGRAPHIC ATROPHY}

In geographic or areolar atrophy, the RPE disappears and the choriocapillaris becomes markedly atrophied. Consequently, the vessels of the choroid are visible by funduscopic evaluation (Fig. 23). Photoreceptor cell loss is seen, because the photoreceptors are metabolically dependent on the RPE (Green et al., 1985). This is best indicated on histological examination by a gradual loss of the outer nuclear layer of the retina, which results in a direct and firm contact between Bruch's membrane, and the outer plexiform layer of the retina (Fig. 19). The loss of the RPE and photoreceptors occurs in advance of the choriocapillaris atrophy. The firm contact of the outer plexiform layer with Bruch's membrane, is one of the reasons why geographic atrophy prevents the development of a serous or hemorrhagic detachment of the retina in the same area (Sarks et al., 1988). It has also been postulated that new vessel formation is dependent on viable RPE, and thus can only occur outside the area of atrophy (Sarks et al., 1988). The edge of the atrophic area is called the junctional zone. This zone is marked by several layers of hypertrophic RPE cells, and BLD is often present (Fig. 19). Neovascularization, if present, tends to occur in this zone, sometimes accompanied by giant cells and macrophages (Green and Key, 1977; Sarks et al., 1988; Schatz and McDonald, 1989; van der Schaft et al., 1993). The remaining visual acuity is dependent on the site and the extent of the geographic atrophy. If it is in the foveola, the visual acuity will (most often) decrease to the level of finger counting.

\section{NEOVASCULAR OR DISCIFORM MACULAR DEGENERATION}

In some aged eyes, new subretinal vessels have been found between the RPE and Bruch's membrane, which can be seen on funduscopic examination (Fig. 24) and more markedly on fluorescein angiography. This process takes place, preferentially, in the presence of a thick layer of BLD (Blumenkranz et al., 1986; Sarks, 1975, 1976; Sarks et al., 1980) and soft drusen (Green et al., 1985). These abnormal vessels originate from the 
choriocapillaris, and penetrate Bruch's membrane by pre-existing, or newly formed breaks. The new vessels tend to exudate serous fluid, proteins, lipids, or blood under the RPE, often leading to an RPE detachment (Green, 1985; Green et al., 1985). This fluid might even break through the RPE monolayer, and cause an overlying neurosensory detachment. This type of AMD is, therefore, often called the neovascular, exudative, or "wet" type of AMD (Fig. 25) and because of the discshaped RPE detachment, and the resulting fibrovascular scar, it is also called the "disciform" type of AMD. The induction of angiogenesis in AMD has been suggested to be caused by macrophages (Penfold et al., 1990; van der Schaft et al., 1993). These macrophages are seen at the choroidal side of Bruch's membrane in eyes with a disciform reaction. In these maculae, Bruch's membrane is thinner than normal for that age, and is sometimes even discontinuous (Sarks, 1970; van der Schaft et al., 1993). Although it seems likely that growth factors such as transforming growth factors and fibroblast growth factors are involved in the process of neovascularization (Amin et al., 1994), there is no proof that they are the initiating factors. Subretinal neovascularization is often accompanied by a low-grade chronic inflammatory reaction, as seen in histological sections (Sarks et al., 1988). A subsequent fibrovascular, disciform scar, is formed by fibroblasts that invade and organize the hemorrhage (Green et al., 1985). The overlying RPE cells and photoreceptors are separated from their supply of nutrients from the choriocapillaris, by the scar. The RPE cells are shifted laterally and start to clump, which often results in clusters of pigmented cells, buried in a thick fibrotic scar. They become atrophic and finally disappear. The result is a disciform scar in the macula (Fig. 20A and B). Since the histological abnormalities, leading to neovascularization, extend over several disc diameters, the disciform response can be multifocal, and particularly endanger the fovea, where the changes are generally most severe (Fig. 26).

The neovascular form of AMD has been found in 0.5\% of the population (Bressler et al., 1989). Between 55 and 64 years it is $0.1 \%$, but over 85 years the prevalence is $7.4 \%$ (Vingerling et al., 1994). Disciform lesions account for $80-90 \%$ of blindness due to AMD (Hyman et al., 1983; Young, 1988). AMD is often bilateral, but an interval of several years between fellow eyes in the development of AMD is usually seen (Lavin et al., 1991). Patients with the exudative form of AMD have a yearly risk of $12 \%$ of developing an exudative lesion in the contralateral eye (Ferris, 1983). Of the patients with this form of AMD, 70\% will develop a seriously diminished visual acuity (less than 1/10) within 24 months (Blumenkranz et al., 1986).

\section{CONCLUSIONS}

The different morphologic changes described in the previous sections are related to the development of ARM. However, there are several variations in the evolution of ARM to AMD. The most prominent morphologic changes supposedly leading to AMD are soft drusen and BLD. Soft drusen can be seen in vivo by ophthalmoscopic examination, but BLD is only histologically visible, and can not be clinically recognized. The amount of the deposits seems to affect the pathogenesis and severity of ARM. A considerable amount of histopathological research has been done on these deposits, but their chemical composition, which might be important in the development of AMD (Bird, 1992; Sheraidah et al., 1993; van der Schaft et al., 1992a), has only been partly resolved. This information is necessary for further study on the source of the deposits, and the natural course of ARM. Since there is still no adequate therapy for the severely invalidating AMD, and because of the aging population resulting in even more patients with this disease, it is necessary to intensify the research on ARM in order to prevent AMD, or find a sufficient therapy for it.

\section{REFERENCES}

Amin, R., Puklin, J.E., and Frank, R.N. (1994) Growth factor localization in choroidal neovascular membranes of age-related macular degeneration. Invest. Ophthalmol. Vis. Sci., 35:3178-3188.

Bird, A.C. (1991) Pathogenesis of retinal pigment epithelial detachment in the elderly; The relevance of Bruch's membrane change. Eye, $5: 1-12$

Bird, A.C. (1992) Bruch's membrane change with age. Br. J. Ophthalmol., 76:166-168.

Bird, A.C., and Marshall, J. (1986) Retinal pigment epithelial detachments in the elderly. Trans. Ophthalmol. Soc. U.K., 105:674-682.

Blumenkranz, M.S., Russell, S.R., Robey, M.G., Kott Blumenkranz, R., and Penneys, N. (1986) Risk factors in age-related maculopathy complicated by choroidal neovascularization. Ophthalmology, 96: $552-558$

Boulton, M., Moriarty, P., Jarvis-Evans, J., and Marcyniuk, B. (1994) Regional variations and age-related changes of lysosomal enzymes in the human retinal pigment epithelium. Br. J. Ophthalmol., $78: 125-129$.

Bressler, N.M., Bressler, S.B., West, S.K., Fine, S.L., and Taylor, H.R. (1989) The grading and prevalence of macular degeneration in Chesapeake Bay watermen. Arch. Ophthalmol., 107:847-852.

Burns, R.P., and Feeney-Burns, L. (1980) Clinico-morphologic correlations of drusen of Bruch's membrane. Trans. Am. Ophthalmol. Soc. 78:206-222

Campochiaro, P.A., Jerdon, J.A., and Glaser, B.M. (1986) The extracellular matrix of human retinal pigment epithelial cells in vivo and its synthesis in vitro. Invest. Ophthalmol. Vis. Sci., 27:1615-1621.

Coffey, A.J.H., and Brownstein, S. (1986) The prevalence of macular drusen in postmortem eyes. Am. J. Ophthalmol., 102:164-171.

Curcio, C.A., Millican, C.L., Allen, K.A., and Kalina, R.E. (1993) Aging of the human photoreceptor mosaic: Evidence for selective vulnerability of rods in central retina. Invest. Ophthalmol. Vis. Sci., 34:32783296 .

Davis, W.L. (1981) An electron microscopic, histochemical and analytical X-ray microanalytical study of calcification in Bruch's membrane from human eyes. J. Histochem. Cytochem., 29:601-608.

Delaney, W.V., and Oates, R.P. (1982) Senile macular degeneration: A preliminary study. Ann. Ophthalmol., 14:21-24.

Dorey, C.K., Wu, G., Ebenstein, D., Garsd, A., and Weiter, J.J. (1989) Cell loss in the aging retina. Invest. Ophthalmol. Vis. Sci., 30:16911699.

Farkas, T.G., Sylvester, V., Archer, D., and Altona, M. (1971) The histochemistry of Drusen. Am. J. Ophthalmol., 71:1206-1215.

Feeney-Burns, L., and Ellersieck, M.R. (1985) Age-related changes in the ultrastructure of Bruch's membrane. Am. J. Ophthalmol., 100:686-697.

Feeney-Burns, L., Berman, E.R., and Rothman, H. (1980) Lipofuscin of human retinal pigment epithelium. Am. J. Ophthalmol., 90:783791.

Feeney-Burns, L., Burns, R.P., and Gao, C.L. (1990) Age-related macular changes in humans over 90 years old. Am. J. Ophthalmol., 109:265-278.

Ferris, F.L. (1983) Senile macular degeneration: Review of epidemiologic features. Am. J. Epidemiol., 118:132-151.

Frank, R.N., Green, W.R., and Pollack, I.P. (1973) Senile macular degeneration: Clinicopathologic correlations of a case in the predisciform stage. Am. J. Ophthalmol., 75:587-594.

Friedman, E., and Tso, M.O.M. (1968) The retinal pigment epithelium. II. Histologic changes associated with age. Arch. Ophthalmol. 79:315-320.

Fryczkowski, A.W., Sherman, M.D., Allinson, R.M., and Payne, C.M 
(1989) Chorioretinal anastomoses in age-related macular degeneration. Ann. Ophthalmol., 21:370-378.

Garron, L.K., Feeney, M.L., Hogan, M.J., and McEwen, W.K. (1958) Electron microscopic studies of the human eye. Am. J. Ophthalmol., 27-35.

Glaser, B.M., Campochiaro, P.A., Davis, J.L.J., and Sato, M. (1985) Retinal pigment epithelial cells release an inhibitor of neovascularization. Arch. Ophthalmol., 103:1870-1875.

Green, W.R. (1985) Pathology of the macula. In: Ophthalmic Pathology: An Atlas and Textbook. W.H. Spencer, ed. Saunders, Philadelphia, pp. 924-989.

Green, W.R., and Enger, C. (1993) Age-related macular degeneration histopathologic studies. The 1992 Lorenz E. Zimmerman Lecture. Ophthalmology, 100:1519-1535.

Green, W.R., and Key, S.N. (1977) Senile macular degeneration: A histopathologic study. Trans. Am. Ophthalmol. Soc., 75:180-254.

Green, W.R., McDonnell, P.J., and Yeo, J.H. (1985) Pathologic features of senile macular degeneration. Ophthalmology, 92:615-627.

Grindle, C.F.J., and Marshall, J. (1978) Ageing changes in Bruch's membrane and their functional implications. Trans. Ophthalmol. Soc. U.K., 98:172-175.

Haab, O. (1888) Ueber die Erkrankung der Macula lutea. Periodischer internationaler Ophthalmologen Congress, Heidelberg, Germany 429-437.

Hewitt, A.T., Nakazawa, K., and Newsome, D.A. (1989) Analysis of newly synthesized Bruch's membrane proteoglycans. Invest. Ophthalmol. Vis. Sci., 30:478-486.

Hogan, M.J. (1972) Role of the retinal pigment epithelium in macular disease. Trans. Am. Acad. Ophthalmol. Otol., 76:64-80.

Hogan, M.J., Alvarado, J.A., and Weddell, J.E. (1971). Histology of the Human Eye. Saunders Company, Philadelphia.

Hyman, L.G., Lilienfeld, A.M., Ferris, F.L., and Fine, S.L. (1983) Senile macular degeneration: A case control study. Am. J. Epidemiol., 118:213-227.

Ishibashi, T., Patterson, R., Ohnishi, Y., Inomata, H., and Ryan, S.J (1986) Formation of drusen in the human eye. Am. J. Ophthalmol. 101:342-353.

Kenyon, K.R., Maumenee, A.E., Ryan, S.J., Withmore, P.V., and Green, W.R. (1985) Diffuse drusen and associated complications. Am. J. Ophthalmol., 100:119-128.

Killingsworth, M.C. (1987) Age-related components of Bruch's membrane in the human eye. Graefe's. Arch. Clin. Exp. Ophthalmol. 225:406-412.

Killingsworth, M.C., Sarks, J.P., and Sarks, S.H. (1990) Macrophage related to Bruch's membrane in age-related macular degeneration Eye, 4:613-621.

Klein, B.E., and Klein, R. (1982) Cataracts and macular degeneration in older Americans. Arch. Ophthalmol., 100:571-573.

Kliffen, M., Mooy, C.M., Luider, T.M., and de Jong, P.T.V.M. (1994) Analysis of carbohydrate structures in basal laminar deposit in aging human maculae. Invest. Ophthalmol. Vis. Sci., 35:2901-2905.

Kliffen, M., de Jong, P.T.V.M., and Luider, T.M. (1995) Protein analysis of human maculae in relation to age-related maculopathy. Lab. Invest., 73:267-272.

Kliffen, M., Mooy, C.M., Luider, T.M., Huÿmans, J.G.M., Kerkuliel, S., de Jong, P.T.V.M. (1996) Identification of glycosaminoglycans in age-related macular deposits. Arch. Ophthalmol., 114:1009-1014

Korte, G.E., Reppucci, V., and Henkind, P. (1984) RPE destruction causes choriocapillary atrophy. Invest. Ophthalmol. Vis. Sci., 25: 1135-1145.

Lavin, M.J., Eldem, B., and Gregor, Z.J. (1991) Symmetry of disciform scars in bilateral age-related macular degeneration. Br. J. Ophthalmol, 75:133-136.

Leibowitz, H., Krueger, D.E., Maunder, L.R., Milton, R.C., Kini, M.M. Kahn, H.A., Nickerson, R.J., Pool, J., Colton, T.L., Ganley, J.P., Loewenstein, J.I., and Dawber, T.R. (1980) The Framingham Eye Study Monograph: An ophthalmological and epidemiological study of cataract, glaucoma, diabetic retinopathy, macular degeneration, and visual acuity in a general population of 2631 adults; $1973-1977$. Surv. Ophthalmol., 24:335-610.

Lerman, S. (1988) Ocular phototoxicity. N. Engl. J. Med., 319:14751477

Lewis, H., Straatsma, B.R., and Foos, R.Y. (1986) Chorioretinal juncture. Multiple extramacular drusen. Ophthalmology, 93:10981112

Liles, M.R., Newsome, D.A., and Oliver, P.D. (1991) Antioxidant enzymes in the aging human retinal pigment epithelium. Arch. Ophthalmol., 109:1285-1288

Löffler, K.U., and Lee, W.R. (1986) Basal linear deposit in the human macula. Graefe's. Arch. Clin. Exp. Ophthalmol., 224:493-501.
Marshall, G.E., Konstas, A.G., Reid, G.G., Edwards, J.G., and Lee, W.R. (1992) Type IV collagen and laminin in Bruch's membrane and basal linear deposit in the human macula. Br. J. Ophthalmol., 76:607-614

Moore, D.J., Hussain, A.A., and Marshall, J. (1994) Fluid dynamics of the aging Bruch's-choroid complex. Invest. Ophthalmol. Vis. Sci., 35:1502 (abstract 1141)

Nakaizumi, Y. (1964) The ultrastructure of Bruch's membrane III. The macular area of the human eye. Arch. Ophthalmol., 72:395-401.

Pauleikhoff, D., Barondes, M.J., Minassian, D., Chisholm, I.H., and Bird, A.C. (1990a) Drusen as risk factors in age-related macular disease. Am. J. Ophthalmol., 109:38-43.

Pauleikhoff, D., Chen, J.C., Chisholm, I.H., and Bird, A.C. (1990b) Choroidal perfusion abnormality with age-related Bruch's membrane change. Am. J. Ophthalmol., 109:211-217.

Pauleikhoff, D., Harper, C.A., Marshall, J., and Bird, A.C. (1990c) Aging changes in Bruch's membrane. A histochemical and morphoogic study. Ophthalmology, 97:171-178.

Pauleikhoff, D., Wessing, A., Marshall, J., and Bird, A.C. (1992a) Lipids in Bruch's membrane: A pathogenetic factor in age-related pigment epithelial detachment. Chibret. Int. J. Ophthalmol. 9:62-69.

Pauleikhoff, D., Zuels, S., Sheraidah, G.S., Marshall, J., Wessing, A. and Bird, A.C. (1992b) Correlation between biochemical composition and fluorescein binding of deposits in Bruch's membrane. Ophthalmology, 99:1548-1553.

Penfold, P., Provis, J.M., Madigan, M.C., van Driel, and Bilson, F.A (1990) Angiogenesis in normal human retinal development: The involvement of astrocytes and macrophages. Graefe's. Arch. Clin Exp. Ophthalmol., 228:255-263.

Ramrattan, R.S., van der Schaft, T.L., Mooy, C.M., de Bruyn, C.M. Mulder, P.G.H., and de Jong, P.T.V.M. (1994) Morphometric analysis of Bruch's membrane, the choriocapillaris and the choroid in aging. Invest. Ophthalmol. Vis. Sci., 35:2857-2864.

Sarks, S.H. (1970) The fellow eye in senile disciform degeneration. Trans. Aust. Coll. Ophthalmol., 2:77-82.

Sarks, S.H. (1973) Senile choriodal sclerosis. Br. J. Ophthalmol., 57:98-109.

Sarks, S.H. (1975) The aging eye. Med. J. Aust., 2:602-604

Sarks, S.H. (1976) Ageing and degeneration in the macular region: A clinico-pathological study. Br. J. Ophthalmol., 60:324-341.

Sarks, S.H. (1980) Drusen and their relationship to senile macular degeneration. Austr. J. Ophthalmol., 8:117-130.

Sarks, S.H. (1982) Drusen patterns predisposing to geographic atrophy of the retinal pigment epithelium. Austr. J. Ophthalmol., 10:91-97.

Sarks, S.H., van Driel, D., Maxwell, L., and Killingsworth, M.C. (1980) Softening of drusen and subretinal neovascularization. Trans. Ophthalmol. Soc. U.K., 100:414-422.

Sarks, J.P., Sarks, S.H., and Killingsworth, M.C. (1988) Evolution of geographic atrophy of the retinal pigment epithelium. Eye, 2:552577.

Schatz, H., and McDonald, H.R. (1989) Atrophic macular degeneration. Rate of spread of geographic atrophy and visual loss. Ophthalmology, 96:1541-1551.

Sheraidah, G., Steinmetz, R., Maguire, J., Pauleikhoff, D., Marshall, J., and Bird, A.C. (1993) Correlation between lipids extracted from Bruch's membrane and age. Ophthalmology, 100:47-51.

Tso, M.O.M. (1985) Pathogenetic factors of aging macular degeneration. Ophthalmology, 92:628-635.

Tso, M.O.M., and Friedman, E. (1967) The retinal pigment epithelium. I. Comparative histology. Arch. Ophthalmol., 78:641-649.

Ulshafer, R.J., Allen, C.B., and Rubin, M.L. (1990) Distributions of elements in the human RPE. Arch. Ophthalmol., 108:113-117.

van der Schaft, T.L., de Bruijn, W.C., Mooy, C.M., Ketelaars, D.A., and de Jong, P.T.V.M. (1991) Is basal laminar deposit unique for agerelated macular degeneration? Arch. Ophthalmol., 109:420-425.

van der Schaft, T.L., de Bruijn, W.C., Mooy, C.M., Ketelaars, D.A., and de Jong, P.T.V.M. (1992a) Element analysis of the early stages of age-related macular degeneration. Arch. Ophthalmol., 110:389-394.

van der Schaft, T.L., de Bruijn, W.C., Mooy, C.M., Oron, F.G., Mulder, P.G., and de Jong, P.T.V.M. (1992b) Histologic features of the early stages of age-related macular degeneration. A statistical analysis Ophthalmology, 99:278-286.

van der Schaft, T.L., Mooy, C.M., de Bruijn, W.C., and de Jong, P.T.V.M (1993) Early stages of age-related macular degeneration: An immunofluorescence and electron microscopy study. Br. J. Ophthalmol., 77:657-661.

van der Schaft, T.L., Mooy, C.M., de Bruijn, W.C., Bosman, F.T., and de Jong, P.T.V.M. (1994) Immunohistochemical light and electron mi- 
croscopy of basal laminar deposit. Graefe's. Arch. Clin. Exp. Ophthalmol., 232:40-46.

Vinding, T. (1989) Age-related macular degeneration. Macular changes, prevalence and sex ratio. Acta Ophthalmol., 67:609-616.

Vingerling, J.R., Dielemans, I., Hofman, A., Hijmering, M.L., Kramer, S.L., Grobbee, D.E., and de Jong, P.T.V.M. (1995) The prevalence of age-related maculopathy in the Rotterdam Study. Ophthalmology, 102:205-210.

Weiter, J.J., Delori, F.C., Wing, G.L., and Fitch, K.A. (1985) Relationship of senile macular degeneration to ocular pigmentation. Am. J. Ophthalmol., 99:185-187.

Weiter, J.J., Delori, F.C., Wing, G.L., and Fitch, K.A. (1986) Retinal pigment epithelial lipofuscin and melanin and choroidal melanin in human eyes. Invest. Ophthalmol. Vis. Sci., 27:145-152.

Wells, K.K., Folberg, R., Goeken, J.A., and Kemp, J.D. (1989) Temporal artery biopsies. Correlation of light microscopy and immunofluorescence microscopy. Ophthalmology, 96:1058-1064.

Young, R.W. (1988) Solar radiation and age-related macular degeneration. Surv. Ophthalmol., 32:252-269.

Yurchenco, P.D., and Furthmayr, H. (1984) Self-assembly of basement membrane collagen. Biochemistry, 23:1839-1850.

Zrenner, E. (1990) Lichtinduzierte Schäden am Auge. Fortschr. Ophthalmol., 87:41-51. 